\title{
地质微生物功能群: 生命与环境相互作用的重要突破口
}

\author{
谢树成 ${ }^{(1)}$, 杨欢 ${ }^{(1)}$, 罗根明 ${ }^{(2)}$, 黄咸雨 ${ }^{(2)}$, 刘邓 ${ }^{(1)}$ ，王永标 ${ }^{(2)}$ 龚一鸣 ${ }^{(1)}$, 徐冉 ${ }^{(1)}$
}

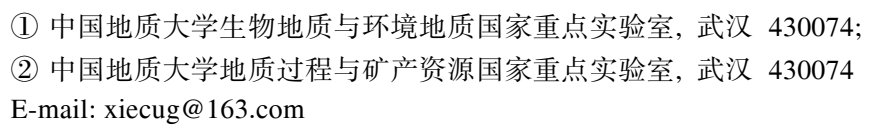

(1) 中国地质大学生物地质与环境地质国家重点实验室, 武汉 430074;

(2) 中国地质大学地质过程与矿产资源国家重点实验室, 武汉 430074

E-mail: xiecug@163.com

2011-08-01 收稿, 2011-10-24 接受

国家自然科学基金重点项目(40930210,41130207)、国家自然科学基金委员会创新研究群体科学基金(40921062)、国家重点基础研究发展 计划(2011CB808800)和高等学校学科创新引智计划(B08030)资助

\begin{abstract}
摘要 微生物类型丰富、数量巨大, 是联系其他生物和环境的重要纽带. 但由于在地质体中保 存下来的细菌和古菌缺乏形态和结构的多样性, 不能像动植物那样可以从形态上开展属种水 平的研究, 这个难点问题一直影响着地质微生物的研究. 地质微生物功能群因在生理学、生态 学和生物地球化学等方面的功能明确, 并能在地质体中留下各种记录而将成为瓶颈突破的关 键点, 它是当前古生物学向地球生物学发展的一个重点研究内容. 本文评述了与碳、硫、氮和 铁等重要元素代谢和循环有关的地质微生物功能群的特点、起源及其在地质体中的识别标志, 分析了这些微生物功能群在参与形成地质历史时期的异常气候、硫化海洋、低浓度硫酸盐海 洋、地质营养条件以及前寒武纪条带状铁建造等方面的重要作用。
\end{abstract}

关键词

地质微生物

功能群

碳一硫-氮循环

铁氧化还原

光合作用

分子化石

地球生物学

地质突变期

\section{1 突破地质微生物功能群的重要性}

认识重大地质环境演变的整体规律，必须弄清 生命与环境的相互作用. 这是因为自从生命出现以 来, 生命与其环境一直在相互作用, 并最终形成了人 们现在所看到的地球生态系统. 在阐述生物圈与地 球系统的相互作用中, 过去的研究偏重于地球环境 变化对生物的影响, 倾向地认为生物圈的演化只是 被动地适应地球环境的变迁. 例如, 与地幔柱动力学 过程密切相关的大规模、快速火山喷发导致大气圈和 海洋环境的变化, 从而影响生物圈的演化 ${ }^{[1]}$. 需要强 调的是, 生物圈反过来也以多种方式(生命过程)改变 着地球表层环境的物理和化学要素, 生命过程与地 球系统的物理和化学过程紧密相关, 它们一起构成 了地球系统的三大物质运动形式. 生命过程对地球 系统动力学过程起着重要的调节和缓冲等反馈作 用 ${ }^{[2 \sim 4]}$. 然而, 长期以来人们对地球历史上生命作用 于环境的认识比较薄弱、研究滞后, 这已经影响了人
们对重大地质环境突变的认识, 并进一步阻碍了人 们对行星地球的整体认识.

要突破人们现有的生命对地质环境作用的有限 认识, 一个关键点在微生物的地质过程 ${ }^{[4]}$. 在生命的 系统演化树上，微生物构成了全部的细菌和古菌以 及大部分真核生物. 在生态系统中, 微生物向上作用 于动物和植物, 向下则直接作用于自然环境; 微生物 既是生产者又是分解者, 通过能量流和物质流直接 对地质环境发生作用 ${ }^{[5]}$. 然而, 以细菌和古菌为代表 的地质微生物却是古生物学中的薄弱环节. 产生这 一困境的原因是多方面的. 其中一个重要原因是, 在 各种地质体中保存下来的细菌、古菌等微生物不像多 细胞动植物那样具有形态和结构的多样性, 人们难 以从形态上对这些地质微生物进行分门别类, 并开 展属种水平的研究.

如何解决地质微生物研究所面临的这个瓶颈问 题? 由于微生物参与的地质过程主要与一些特征性 的微生物功能群有关 ${ }^{[6,7]}$, 为了克服目前地质微生物

英文版见: Xie S C, Yang H, Luo G M, et al. Geomicrobial functional groups: A window on the interaction between life and environments. Chin Sci Bull, 2012, 57: 2-19, doi: $10.1007 / \mathrm{s} 11434-011-4860-\mathrm{x}$ 
分门别类的困难, 可以把研究从庞大的微生物体系 中聚焦在地质微生物功能群上, 特别是那些与碳、氮、 硫、铁等元素的代谢有关的功能群. 微生物功能群是 指具有特定功能的微生物集群, 这些功能多种多样, 包括生理学、生态学和生物地球化学等功能. 例如, 具有固定 $\mathrm{N}_{2}$ 功能的固氮微生物功能群. 功能群与生 物分类类群不同，同一功能群可以来自不同的分类 类群. 地质微生物主要通过这些功能群对地质环境 起作用. 功能群直接将微生物的特定功能与环境变 化紧密联系起来, 也将微生物的生态学与其生物地 球化学联系起来 ${ }^{[6,8]}$. 这使得微生物功能群可以在沉 积物和岩石中留下一系列的标志, 如分子化石、微生 物的各种地球化学指纹、微生物成因矿物、微生物沉 积组构等. 各种分子和同位素技术、微区分析技术等 为研究这些宏观、微观标志提供了重要手段. 不管是 对这些微生物功能群标志的识别, 还是对这些技术 手段的发展, 在以前的古生物学乃至地质学中是难 以实现的. 突破地质微生物功能群及其地质过程的 时机目前已经成熟. 下面重点评述与碳、硫、氮和铁 这些重要元素的地球化学循环有关的地质微生物功 能群, 包括它们的特征、起源、地质识别标志及其地 质作用等.

\section{2 若干重要地质微生物功能群的特征及其 起源}

\section{1 光合作用微生物功能群及其起源}

光合作用是一种重要的生理代谢途径. 根据电 子供体的不同, 可以分为非产氧和产氧光合作用. 光 合作用微生物功能群在生物演化史上具有重要的意 义, 它的出现增加了固碳所需能量的来源 ${ }^{[9]}$. 早期的 光合生物主要是一些细菌, 包括盐杆菌(halobacteria)、 非硫紫细菌、紫硫细菌、非硫绿细菌、绿硫细菌、太 阳杆菌 (heliobacteria) 和蓝细菌. 在这些光合微生物 中, 只有蓝细菌具有叶绿素, 能进行产氧光合作用. 随后演化出来的藻类是通过与蓝细菌的内共生作用 而获得产氧光合作用的功能 ${ }^{[10]}$.

具有光合作用功能的微生物, 其起源一直是科 学家所关注的问题, 但目前还没有解决. 详细内容可 参考文献[11 14], 这里只简略地介绍一下目前的研 究现状. 地球化学、分子生物学以及古生物学的证据 都表明, 光合作用功能是一种很古老的代谢途径 ${ }^{[14]}$.
分子生物学的研究还进一步表明, 非产氧光合微生 物的起源要早于产氧光合微生物, 且紫色细菌(非硫 紫细菌、紫硫细菌)的起源可能最古老 ${ }^{[15]}$. 由于早期 地球存在还原性大气和海洋, 光合作用主要以非产 氧光合作用为主, 以 $\mathrm{H}_{2}, \mathrm{~S}, \mathrm{H}_{2} \mathrm{~S}$ 和 $\mathrm{Fe}^{2+}$ 等作为电子供 体 ${ }^{[14]}$. 其中, $\mathrm{Fe}^{2+}$ 作为电子供体进行碳的固定备受关 注, 这一代谢在产氧光合作用出现之前已盛行很长 时间. 早期的蓝细菌也被认为是以 $\mathrm{Fe}^{2+}$ 作为电子供体 进行光合作用的 ${ }^{[13]}$, 可能参与了前寒武纪条带状铁 建造的形成 ${ }^{[16 \sim 19]}$.

产氧光合作用的出现是生命史上一个里程碑事 件, 然而对于其起源问题还存在很大的争议 ${ }^{[12]}$. 各 种地球化学指标都明确指示, 地球在 24 亿年左右存 在一次重大的氧化事件 ${ }^{[20]}$ 或者在更早的时间出现过 一次短暂的氧化事件 ${ }^{[21 ~ 23]}$. 这表明产氧光合作用起 源不会晚于这个时间. 目前, 对于产氧光合作用出现 的时间主要有 3 种不同的认识: (1) 起源时间早于地 球的重大氧化事件多达数亿年 ${ }^{[24]}$, 因为氧化地球上 还原性的火山成因气体、热液流体和地壳矿物等需要 很长的时间; (2) 起源时间与大气的氧化时间一致 ${ }^{[25]}$; (3) 在地球很早的时候就已出现, 且早于现有的地质 记录, 从而导致高度氧化的太古代大气 ${ }^{[26]}$. 对于产 氧光合作用的具体起源时间还需要从生物地球化 学、沉积学和矿物学、古生物学等方面做进一步详细 的研究.

藻类的起源相对较晚, 绿藻在元古代晚期才成 为重要的初级生产力贡献者, 而沟鞭藻、颗石藻及硅 藻直到中生代才成为大陆架海域重要的初级生产 者 ${ }^{[27]}$

\section{2 与甲烷有关的微生物功能群}

在当前的全球变化研究中, 比较重视植被生态 系统对全球碳循环的重要影响, 建立了许多模型. 然 而, 微生物功能群也同样重要, 它们通过对 $\mathrm{CO}_{2}$ 和 $\mathrm{CH}_{4}$ 的固定和消耗以及对各种有机质的分解转化, 直 接控制着碳源、碳汇及碳的转化途径。例如，产甲烷 古菌和甲烷氧化古菌/细菌控制着大气甲烷的浓度; 海洋中好氧不产氧光合细菌等微生物将生物可利用 的溶解有机碳转化为难利用的有机碳，使得大量碳 封存于海水中 ${ }^{[28]}$. 由于甲烷是重要的温室气体, 加 上具有极负的碳同位素组成，甲烷在地质历史时期 的变化尤其受到关注. 下面重点介绍与甲烷有关的 
一些微生物功能群, 包括产甲烷古菌、甲烷氧化古 菌、甲烷氧化细菌等.

产甲烷古菌以自养为主, 属于极端厌氧古菌, 广 泛分布于各种缺氧环境中, 如海洋 ${ }^{[29,30]}$ 、湿地尤其是泥 炭地 ${ }^{[31,32]}$. 主要的产甲烷过程包括乙酸盐途径、 $\mathrm{H}_{2} / \mathrm{CO}_{2}$ 途径和甲基化合物途径. 在一些热带雨林地区，凤梨 科植物呈喇叭状的树冠能收集雨水和落叶, 形成了 类似湿地的潮湿环境，从而有利于产甲烷古菌的生 存, 这些地区就成为一个重要的大气甲烷源 ${ }^{[33]}$. 其 他类型的隐形湿地(如竹节、树洞、非凤梨科植物叶 腋)也可能是热带和亚热带森林的甲烷释放源.

自养的甲烷氧化古菌或细菌则消耗环境中的甲 烷. 在深海, 如热液喷口、冷泉和水合物界面, 主要 是由甲烷厌氧氧化古菌和硫酸盐还原细菌共同作用 完成的甲烷厌氧氧化过程 ${ }^{[34,35]}$. 关于甲烷厌氧氧化 的机制, 目前还有争议. 比较公认的说法是, 一些产 甲烷古菌执行产甲烷过程的逆向反应而消耗甲烷 ${ }^{[36]}$. 在陆地淡水环境, 甲烷厌氧氧化古菌与反硝化过程 耦合来完成甲烷的厌氧氧化作用 ${ }^{[37]}$. Ettwig 等人 ${ }^{[38]}$ 从 淡水沉积物中富集到一种厌氧细菌, 它能通过产生 氧气用于甲烷的有氧氧化. 这是一种全新的产氧模 式, 具有非常重要的生物地球化学和进化上的意义.

在泥炭环境, 甲烷的氧化主要由好氧的甲烷氧 化细菌完成. 在好氧条件下, 甲烷氧化细菌将甲烷和 氧分子结合成甲醛, 然后通过丝氨酸途径或 RuMP 途 径转化为有机物. 根据形态、 DNA 中 $\mathrm{G}+\mathrm{C}$ 含量、代 谢途径、膜结构和磷脂脂肪酸组成可将甲烷氧化细菌 划为 3 类 ( I 型、II 型和 X 型). 其中, I 型采用 RuMP 途径同化甲醛, 属于 $\gamma$-变形菌纲; II 型采用丝氨酸途 径同化甲醛, 属于 $\alpha$-变形菌纲; $\mathrm{X}$ 型主要采用 RuMP 途径同化甲醛, 同时含有低水平的丝氨酸途径, 属于 疮微菌门 ${ }^{[39]}$.

\section{3 与硫代谢相关的微生物功能群及其起源}

硫代谢是地球早期生命获取能量的主要形式之 一, 作为最接近最早共同祖先的嗜超高压细菌/古菌 也主要是利用硫代谢来获取能量 ${ }^{[40]}$. 研究硫代谢微生 物的起源和演化对了解生命的起源和演化以及探索地 外生命具有非常重要的意义. 与硫循环有关的代谢主 要有硫酸盐还原、硫还原、硫的歧化、硫的厌氧氧化 以及硫的好氧氧化等, 涉及到的微生物功能群主要有 硫酸盐还原细菌和古菌、硫还原细菌和古菌、硫的歧
化细菌、硫的厌氧氧化细菌和好氧氧化细菌(图 1).

具有硫酸盐还原功能的微生物主要是细菌, 也 有少量的古菌. 两者都是严格的厌氧微生物. 硫酸盐 还原细菌以 $\delta$-变形菌纲(革兰氏阴性菌)为主, 少量的 革兰氏阳性菌和嗜热细菌(Thermodesulfobacterium 和 Thermodesulfovibrio $)^{[41]}$. 硫酸盐还原古菌目前发现的 还很少, 主要是一些高温热泉古菌(Archaeoglobus) ${ }^{[41]}$. 根据硫同位素资料, 硫酸盐还原微生物最早大约在 34.7 亿年前就出现了 ${ }^{[42,43]}$. 目前有关这些硫酸盐还 原微生物是细菌还是古菌(虽然一般都认为是细菌), 以及古菌在硫酸盐还原过程所产生的硫同位素分馏 还了解得比较少 ${ }^{[44]}$.

硫的歧化细菌是一类厌氧的自养细菌 ${ }^{[45]}$. 这类 细菌的起源备受关注, 因为在硫的歧化过程中会形 成特征性的硫同位素分馏效应 $\left(\Delta^{34} S>46 \% \text { o }\right)^{[46]}$. 通过 对多硫同位素的分析, Johnston 等人 ${ }^{[47]}$ 认为硫的歧化 细菌可能在中元古代(约 13 亿年前)就已出现. Parnell 等人 ${ }^{[48]}$ 把中元古代末期(约 11.8 亿年前)陆相地层存在 的大的硫同位素分馏(大于 50\%o) 归因于大气氧含量 升高而引起的硫的歧化代谢. 最近, 多硫同位素的微 区研究表明, 硫酸盐的细菌还原作用和硫的歧化作 用这两种代谢可能在 34 亿年前都已存在 ${ }^{[49]}$. 越来越 多的证据表明, 从硫酸盐到 $\mathrm{S}^{2-}$ 的还原过程也能够产 生很大 $\left(\Delta^{34} \mathrm{~S}>46 \%\right)$ 的硫同位素分馏 ${ }^{[00 ~ 52]}$. 这些工作 对硫的歧化代谢可以指示前寒武纪高含量氧气的假 说 ${ }^{[33]}$ 提出了质疑.
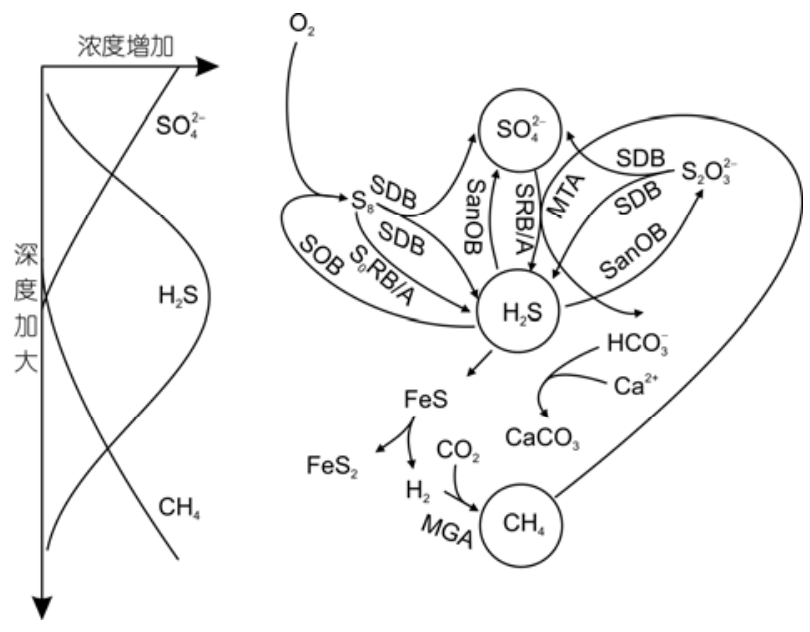

图 1 硫循环及其相关的微生物功能群

$\mathrm{SRB} / \mathrm{A}$, 硫酸盐还原细菌/古菌; SDB, 硫的歧化细菌; SanOB, 硫的厌 氧氧化细菌; SOB, 硫的好氧氧化细菌; $\mathrm{S}_{0} R B / A$, 硫还原细菌/古菌; MGA, 产甲烷古菌; MTA, 甲烷氧化古菌 
硫的厌氧氧化细菌主要包括绿硫细菌和紫硫细 菌. 两者都属于不产氧光合自养生物, 利用太阳能并 以 $\mathrm{H}_{2} \mathrm{~S}$ 作为电子供体进行 $\mathrm{CO}_{2}$ 的固定, 一般生活在富 含 $\mathrm{H}_{2} \mathrm{~S}$ 的透光层. 目前的证据表明, 这类微生物功能 群的起源不会晚于 16 亿年 ${ }^{[54]}$. 这些微生物在前寒武 纪地层中很少报道, 但经常出现在显生宙的缺氧环 境 ${ }^{[5]}$. 这可能是由于前寒武纪地层的有机质成熟度 普遍很高, 使这些细菌的分子化石遭到破坏. 同时, 由于前寒武纪海洋的硫酸盐浓度一直很低, 也可能 导致了这类微生物难以繁盛.

硫的好氧氧化细菌进行硫氧化时需要一定的氧 气. 很多人认为这类微生物的起源较晚. 分子化石和 古生物的工作表明, 这类微生物在 16.4 亿年前就已 存在 ${ }^{[56]}$. 但是, 一些研究发现, 硫的氧化代谢可能并 不需要氧气. 在现代黑海中, 硫化物氧化细菌主要出 现在化学跃变层之下的含硫化氢环境 ${ }^{[7]}$. 一些研究 也表明, 硫氧化细菌能够以硝酸盐作为电子受体进 行硫的氧化代谢 ${ }^{[58]}$. Wacey 等人 ${ }^{[59]}$ 则提出硫的氧化 代谢在 34 亿年前就已存在.

硫还原代谢是一种古老的、产能很低的代谢方 式 ${ }^{[41]}$. 营此代谢功能的微生物主要有硫还原细菌和 硫还原古菌. 它们是厌氧异养微生物, 但也有少量能 够进行好氧代谢 ${ }^{[41]}$. 这些微生物除了能还原硫外, 亦能还原其他的氧化物, 如锰(IV)和 $\mathrm{Fe}(\mathrm{III})$ 等 $^{[41]}$. 目 前所发现的硫还原古菌, 都是一些极端嗜热微生物, 主要生活在热泉环境. 目前人们对这类微生物在地 质历史上的起源和演化还了解得很少.

\section{4 与氮代谢相关的微生物功能群及其起源}

作为控制初级生产力的关键元素, 氮对海洋生 产力的制约作用甚至超过了磷 ${ }^{[60]}$. 在各种形态氮的 转换中, 微生物作用至关重要(图 2). 这些微生物实 际上是驱动地球生态系统氮循环的一个强有力的引 擎 ${ }^{[8]}$.

大多数生物不能直接利用氮气，而固氮微生物 能够将氮气转化为生物可利用的铵态氮, 从而进人合 成生物体的蛋白质和核酸等生命物质中去 ${ }^{[8]}$. 固氮微 生物功能群在海洋和陆地环境有着明显的差异. 在海 洋中, 最主要的固氮微生物是蓝细菌 Trichodesmium. 新发现了一些能够生存于高纬度和深水等葟营养海 区的单细胞蓝细菌, 如 Crocosphaera watsonii, 其生 物量和固氮速率都不逊色于 Trichodesmium. 这些单
细胞蓝细菌已成为人们认识海洋氮循环不可忽视的 一股新力量 ${ }^{[61]}$. 蓝细菌固氮功能主要受 nif $\mathrm{H}$ 基因调 控 ${ }^{[62]}$, nif $\mathrm{H}$ 基因能够表达合成固氮酶中的关键蛋白, 即铁/钼硫化物蛋白. 因此, $\mathrm{Fe}$ 和 $\mathrm{Mo}$ 等金属元素的获 取在一定程度上限制和影响了微生物的固氮作用 ${ }^{[63]}$. 在陆地环境中, 固氮微生物则主要是植物根系的根 瘤菌和一些游离的固氮细菌和古菌. 在现代微生物 席中, 蓝细菌和 $\gamma$-变形菌纲出现在同一微生物群落 中, 共同构成了微生物席中的固氮微生物功能群. 但 它们固氮的时间并不一样. 蓝细菌主要在白天至午 夜固氮, 而午夜至天明则主要由 $\gamma$-变形菌纲进行固 氮 ${ }^{[64]}$.

微生物固定的铵态氮可直接被生物利用, 或进 一步被氨氧化微生物功能群氧化成 $\mathrm{NO}_{2}^{-}$(图 2). 参与 氨氧化的微生物最初只发现有氨氧化细菌( $\mathrm{AOB})$, 分 类上主要集中于 $\beta$-和 $\gamma$-变形菌纲, 且都为专性好氧 的化能自养型细菌 ${ }^{[65]}$. 然而, Leininger 等人 ${ }^{[66]}$ 通过对 氨氧化过程中起关键作用的氨单加氧酶基因 $(a m o \mathrm{~A})$ 进行 Q-PCR 定量, 发现现代土壤中氨氧化古菌(AOA) 的数量要明显高于 $\mathrm{AOB}$, 是土壤中最主要的氨氧化 微生物. 同样, 在包括海洋水柱和沉积物、湖泊沉积 物在内的大部分地质环境中, $\mathrm{AOA}$ 较之 $\mathrm{AOB}$ 在数量 上都具有明显的优势 ${ }^{[67]}$. AOA 序列主要归属于泉古 菌 Group 1.1, 一般为好氧的化能自养型微生物, 利 用乙酰辅酶 $\mathrm{A}$ 羧化酶固定 $\mathrm{CO}_{2}{ }^{[68,69]}$. $\mathrm{AOA}$ 在各种地质 环境中广泛分布, 并具有相对较高的丰度, 表明它们 在全球氮循环中起重要作用. 实验室纯培养的 AOA 可 以在类似于开阔海洋的寡营养环境中保持较高的氨 氧化速率, 其细胞对氨有较高的亲和性. 这些特征使 得 $\mathrm{AOA}$ 在塞营养环境中能够优先获取更多的 $\mathrm{NH}_{4}^{+}$, 从而能够在与异养浮游细菌和藻类的竞争中占据优 势 ${ }^{[70]}$. AOA 和 AOB 的硝化速率会受到环境条件(如 $\mathrm{pH})$ 的影响. 在酸化的海洋中, 氨氧化速率会降低 ${ }^{[71]}$. 这可能使一些地质历史时期的海洋氮库出现巨大的 波动.

目前还没有发现能够将铵态氮直接氧化成 $\mathrm{NO}_{3}^{-}$ 的微生物. $\mathrm{AOA}$ 或 $\mathrm{AOB}$ 先将 $\mathrm{NH}_{4}^{+}$转化为 $\mathrm{NO}_{2}^{-}$, 亚硝 酸盐氧化细菌再把 $\mathrm{NO}_{2}^{-}$进一步氧化成大多数生物可 利用的 $\mathrm{NO}_{3}^{-}$. 与硝化作用不同, 驱动反硝化作用的微 生物可以是细菌、古菌和真菌. 一些底栖有孔虫也能 够独立完成从 $\mathrm{NO}_{3}^{-}$到 $\mathrm{N}_{2}$ 的整个反硝化过程 ${ }^{[72]}$. 反硝 化微生物一般兼性戻氧且异养, 呼吸 $\mathrm{NO}_{3}^{-}$作为最终 


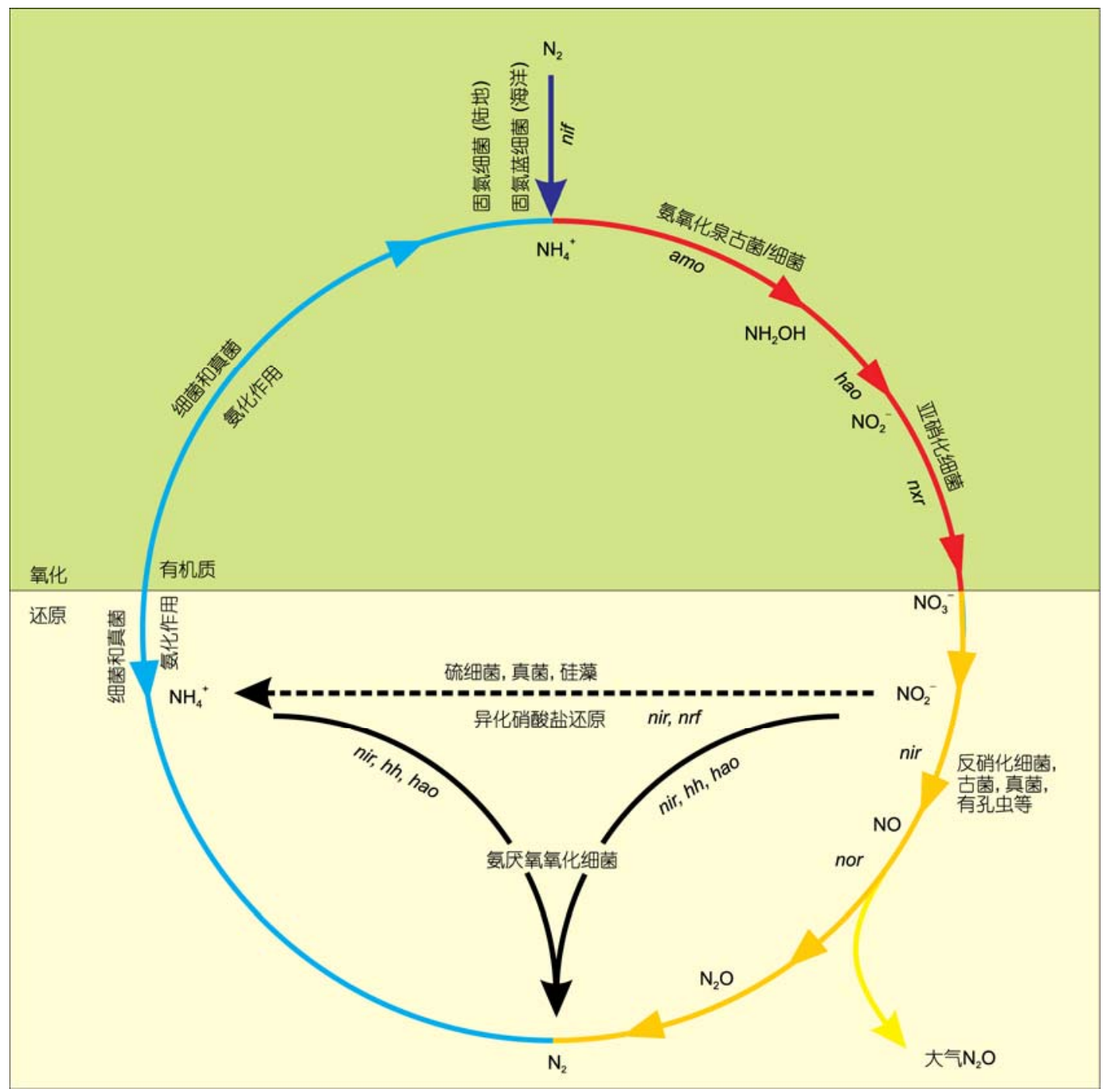

图 2 氮循环及其相关的微生物功能群

$n i f$ 为固氮酶, $a m o$ 为氨单加氧酶, $h a o$ 为羟氨氧化还原酶, $n x r$ 为硝酸盐氧化还原酶, $n i r$ 和 $n r f$ 为亚硝酸盐还原酶, $h h$ 为联氨水解酶, $n o r$ 为 $\mathrm{NO}$ 还原酶. 紫色线为固氮过程, 红线为硝化过程, 黄线为反硝化过程, 蓝线为氨化作用, 黑线为氨厌氧氧化过程, 虚线为异化硝酸盐还原过程

电子受体. $\mathrm{NO}_{3}^{-}$的还原过程需要亚硝酸盐还原酶(nir) 和 $\mathrm{NO}$ 还原酶(nor)等进行催化, 其中间产物 $\mathrm{N}_{2} \mathrm{O}$ 为温 室气体. 在地质历史时期, 大气 $\mathrm{N}_{2} \mathrm{O}$ 含量往往在冰期 较低, 而在间冰期则明显升高, 这表明反硝化作用可 能会通过 $\mathrm{N}_{2} \mathrm{O}$ 影响全球气候 ${ }^{[60]}$. 硝化作用与反硝化 作用的相对强弱使得地质环境的氮循环处于动态平 衡中. 然而, 对氮收支的估算却发现, 现代海洋的氮 损耗比其输人量明显要高 ${ }^{[73]}$. 除了反硝化细菌的作 用外，另外约有 $30 \%$ 50\%的氮损失可能要归功于氨 厌氧氧化细菌 (annamox $)^{[74]}$. 氨厌氧氧化细菌属于浮 霉菌目(Planctomycetales), 生长较为缓慢, 广泛分布
在缺氧的海洋环境、湖泊水体和油田中, 能够在厌氧 环境下将 $\mathrm{NH}_{4}^{+}$和 $\mathrm{NO}_{2}^{-}$转化成 $\mathrm{N}_{2}{ }^{[75,76]}$. 氨厌氧氧化细 菌的深人研究将改变人们对地质环境氮循环的认识, 为地质历史时期氮循环的解译提供一个新思路.

目前有关氮循环微生物功能群起源的认识还处 于初级阶段. 对氮代谢微生物功能群的起源和演化 起关键作用的物质是氧气. 合成固氮酶基因广泛分 布于细菌和古菌中, 而氧气能够抑制固氮酶的生物 活性, 使得现代固氮微生物不得不形成一些特殊结 构(如蓝细菌异形胞和光系统 I), 以便隔绝氧气而维 持固氮功能 ${ }^{[77]}$. 固氮微生物的“始祖”处于系统发育 
树的根部, 很可能出现在大气氧化事件(22 24.5 亿年) 之前 ${ }^{[20,78]}$. 在早期地球环境, 铵态氮和硝态氮的缺乏 会驱动厌氧微生物(如产甲烷古菌等)进化出固氮功 能以维持氮的收支平衡. 绿硫细菌和紫硫细菌等厌 氧光合微生物也有固氮功能, 可能证明了这种进化 关系 ${ }^{[79,80]}$. 硝化细菌/古菌需要氧气来氧化铵根离子, 而反硝化作用和氨厌氧氧化作用则需要氨氧化过程 的产物 $\mathrm{NO}_{3}^{-}$. 只有当蓝细菌等产氧光合微生物出现 以后, 这些微生物功能群才能出现, 并随之构建出氮 循环的现代格架. 沉积有机氮的 $\delta^{15} \mathrm{~N}$ 证据表明, 在 大约 27.2 亿年前的晚太古代可能就已经出现了硝化 作用和反硝化作用 ${ }^{[81]}$.

影响氮循环微生物功能群起源与演化的另一个 重要环境因素是海洋中铁和钼等金属元素的丰度. 铁和锄是固氮酶的辅助因子, 它们参与形成的固氮 酶比其他金属(如钒和镍)形成的固氮酶具有更高的 催化效率，同时它们也是早期地球氧化还原状况的 良好指示计 ${ }^{[82]}$. 太古代的缺氧环境使得大量 $\mathrm{Fe}^{2+}$ 存 在海洋中, 而钿却以还原态被固定在沉积物中, 很难 被生物利用; 元古代的硫化海洋缺铁但钼较太古代有 所增加; 显生宙的氧化海洋则富钿而缺铁 ${ }^{[83]}$. 因此, 只有在 5 6 亿年前深海富氧后, 锄才能更多地被氧化 并最终溶解到海水中, 更高效的固氮酶铁/钿硫化物蛋 白才能大量出现, 从而加速整个海洋氮循环过程.

\section{5 参与铁氧化还原的微生物功能群}

地质微生物功能群通过同化作用和异化作用在 环境中活化或沉淀铁. 铁的同化作用是指铁元素经
微生物吸收作为酶的辅助因子或者直接在细胞内聚 集成矿。趋磁细菌通过同化作用使细胞内含磁小体 而对磁场有趋向性反应, 这类细菌已成为研究铁的 同化作用及矿化控制的模式生物 ${ }^{[84,85]}$. 与同化作用 不同, 异化作用则主要指微生物在细胞外进行铁的 氧化或还原反应以获得能量.

不同微生物功能群与自然界中铁的价态变化紧 密相关(图 3). 在 $\mathrm{pH}$ 中性的有氧条件下, $\mathrm{Fe}$ (II) 可直接 被氧气所氧化, 但在一些特殊环境(如植物根际、热液 喷口等), 以 Gallionella, Leptothrix 及 Marinobacter 为 代表的微生物可通过酶促反应氧化 $\mathrm{Fe}$ (II) 而获得能量 促进生长, 其反应式为 $\left[4 \mathrm{Fe}(\mathrm{II})+\mathrm{O}_{2}+10 \mathrm{H}_{2} \mathrm{O} \rightarrow 4 \mathrm{Fe}(\mathrm{OH})_{3}+\right.$ $\left.8 \mathrm{H}^{+}\right]^{[86,87]}$. 在 $\mathrm{pH}$ 近中性的缺氧环境, $\mathrm{Fe}(\mathrm{II})$ 的微生物 氧化则衍生出其他反应类型. 其中, 不产氧光合细菌 及硝酸盐还原菌是两类主要的铁氧化功能群 ${ }^{[86,87]}$. 不产氧光合铁氧化细菌可来源于不同门类(如 $\gamma$-变形 菌纲紫硫细菌 Thiodictyon sp., $\alpha$-变形菌纲非硫紫细 菌 Rhodobacter ferrooxidans 及 $\delta$-变形菌纲绿硫细菌 Chlorobium ferrooxidans 等), 但其呼吸途径具有类似 性. 它们均以 $\mathrm{Fe}(\mathrm{II})$ 作为电子供体, 同时以光能作为能 量来源固定二氧化碳 ${ }^{[86 ~ 89]}$. 以 Ferroglpbus placidus 为 代表的微生物, 在将硝酸盐还原为氮气的同时能够 氧化 $\mathrm{Fe}(\mathrm{II})^{[86]}$. 这个过程涉及两种机制, 一种为直接 的生物酶促反应, 另一种则为间接的化学反应, 也即 硝酸盐还原的中间代谢产物 $\mathrm{NO}_{2}^{-}$部分地氧化 $\mathrm{Fe}(\mathrm{II})$ $\left[4 \mathrm{Fe}(\mathrm{II})+2 \mathrm{NO}_{2}^{-}+6 \mathrm{H}^{+} \rightarrow 4 \mathrm{Fe}(\mathrm{III})+\mathrm{N}_{2} \mathrm{O}+3 \mathrm{H}_{2} \mathrm{O}\right]^{[90]}$. 不产 氧光合铁氧化细菌及硝酸盐还原菌, 均能氧化可溶性 $\mathrm{Fe}(\mathrm{II})$ 及其矿物 (如菱铁矿、蓝铁矿、磁铁矿及铁的硫

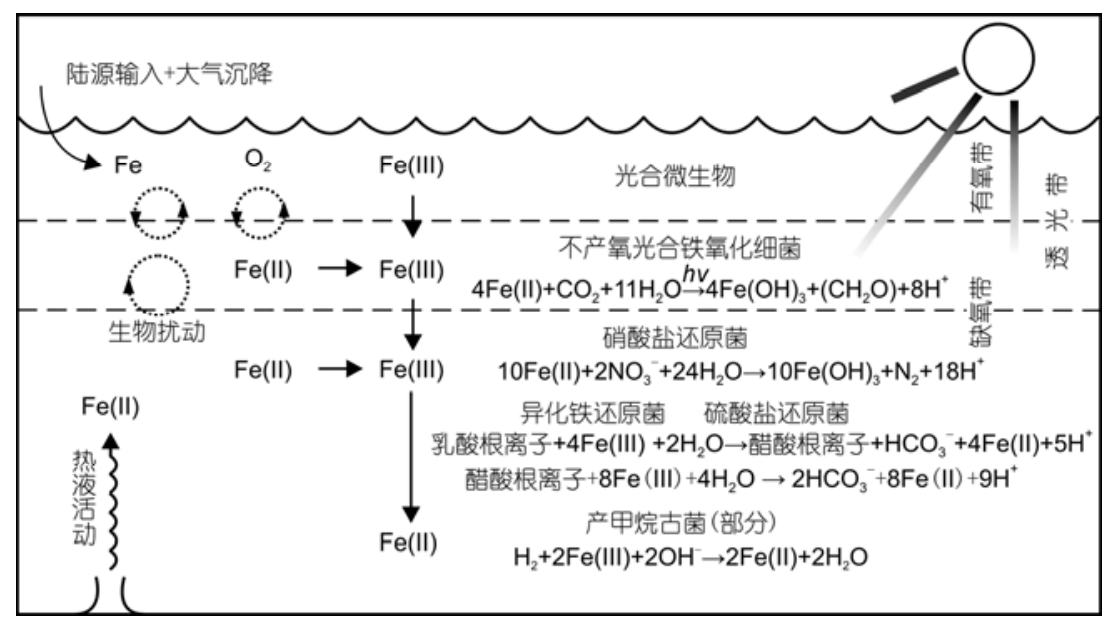

图 3 铁循环及其相关的微生物功能群 
化物矿物等), 同时沉淀出水合氧化铁、针铁矿、纤 铁矿等三价铁矿物 ${ }^{[86,88,90]}$.

$\mathrm{Fe}(\mathrm{III})$ 的微生物还原反应是厌氧环境一类重要 的微生物呼吸途径. 异化铁还原菌通过细胞膜或在 胞内氧化有机物或氢气, 将电子跨膜传递至胞外的 $\mathrm{Fe}(\mathrm{III})$ 矿物, 还原 $\mathrm{Fe}(\mathrm{III})$ 进而获得能量来合成 ATP 促 进细胞生长 ${ }^{[91]}$. 自从 20 世纪 80 年代以 Geobacter 及 Shewanella 为代表的典型菌株相继分离以来 ${ }^{[92,93]}$, $\mathrm{Fe}(\mathrm{III})$ 的微生物异化还原成为地质微生物学乃至微 生物学领域的研究热点. 目前有关异化铁还原菌的 菌株类型、代谢途径及作用机制已得到相对清晰的认 识 ${ }^{[91]}$. 除 Geobacter 及 Shewanella 异化铁还原菌外, 某些营发酵作用的微生物 ${ }^{[94]}$ 、硫酸盐还原菌 ${ }^{[95,96]}$ 及部 分产甲烷古菌 ${ }^{[97,98]}$ 也具备还原 $\mathrm{Fe}(\mathrm{III})$ 的能力. 与厌氧 环境其他电子受体(如硝酸盐、硫酸盐)不同, Fe(III) 主要以固相出现, 如铁的氧化物矿物和含铁硅酸盐 矿物等. 受初始 $\mathrm{Fe}(\mathrm{III})$ 矿物类型及水化学条件等因素 的影响, 微生物还原 $\mathrm{Fe}(\mathrm{III})$ 矿物可生成不同类型的 $\mathrm{Fe}(\mathrm{II})$ 矿物, 如磁铁矿、蓝铁矿、菱铁矿等. 有证据表 明, 微生物呼吸作用可能以 $\mathrm{Fe}(\mathrm{III})$ 作为最早的电子受 体, 这说明微生物铁还原是地球早期生命的代谢形 式之一 ${ }^{[99]}$.

在酸性环境中(如酸性矿山水), 与铁的氧化还原 相关的微生物功能群则呈现与中性环境截然不同的面 貌。在酸性有氧条件下, Acidithiobacillus 及 Leptospirillum 在铁氧化反应中占据优势 ${ }^{[100]}$. 在酸性 缺氧条件下, 以 Acidobacterium 为代表的优势菌群能 够还原铁氧化菌所产生的 $\mathrm{Fe}(\mathrm{III})$ 矿物 $^{[101]}$.

\section{3 地质体中重要微生物功能群的识别标志}

\section{1 光合作用微生物功能群在地质体中的识别}

在地质体中, 大多数光合作用微生物功能群很 难直接从形态上识别出来. 一些地球化学和矿物学 标志也只能通过追踪水体的氧化状况而提供间接的 依据. 经过近些年的发展, 人们发现一些光合作用微 生物功能群具有特征性的生物标志化合物, 从而可 以从分子化石角度进行识别. 蓝细菌的标志化合物 主要是 2-甲基嚄类(包括生物体中的 2-甲基蒦醇及其 成岩转化成的 2-甲基蕉烷), 特别是碳数在 $\mathrm{C}_{31}$ 以上 的同系物 ${ }^{[102]}$. 一些蓝细菌还具有许多中等碳链长度 的单甲基和双甲基的支链烷烃化合物，例如 7-甲基
或 8-甲基十七烷、7,11-二甲基十七烷、4,13-，5,13-， 4,5-二甲基十七烷等 ${ }^{[103]}$. 绿硫细菌的标志化合物为 $1 H$-吡咯-2,5 二酮 ${ }^{[104]}$, 以及 2 -烷基-1,3,4-三甲基苯和 $\mathrm{C}_{40}$ isorenieratene ${ }^{[105]}$. 硅藻的特征标志物主要有 $\mathrm{C}_{25}$ 和 $\mathrm{C}_{30}$ 高支链类异戊二烯烃 ${ }^{[106]}$, 以及 24-降胆甾 烷 ${ }^{[107]}$. 沟鞭澡具有特征的甲藻甾类 $(4 \alpha, 23,24$-三甲基 $-5 \alpha$-胆甾- 22 -烯- $3 \beta$-醇). 颗石藻具有特征的长链不饱 和烯酮 ${ }^{[108]}$. 需要注意的是, 一些生物标志化合物具 有多解性, 如 2-甲基嚾类也在其他细菌中存在.

\section{2 甲烷微生物功能群在地质体中的识别}

与甲烷有关的微生物功能群通常具有特征的类 脂物和单体碳同位素组成, 这为识别地质体中的此 类微生物功能群提供了良好的工具. 现代海底甲烷 喷口的甲烷厌氧氧化古菌主要分 3 类, 即 ANME-1, ANME-2 和 ANME- $3^{[109]}$. ANME-1 主要含 0 3 个五元 环的四醚键化合物(GDGT), ANME-2 主要合成 sn2hydroxyarchaeol 和 crocetane(2,6,11,15-四甲基十六 烷), 而 ANME-3 主要合成 sn2-hydroxyarchaeol 和 PMI 类化合物 $(2,6,10,15,19 \text {-五甲基二十烷 })^{[110]}$. I 型甲 烷氧化细菌可以合成 3-甲基蒦类 ${ }^{[111]}$ 以及 $\mathrm{C}_{16}$ 单不饱 和脂肪酸, 而 II 型甲烷氧化细菌可以合成 $\mathrm{C}_{18}$ 单不饱 和脂肪酸.

除了以上的这些特征性分子外, 甲烷氧化微生 物合成的脂类通常具有明显偏负的碳同位素组成, 这与生物成因的甲烷显著缺乏 ${ }^{13} \mathrm{C}$ 有关. 乙酸盐途径 合成甲烷的 $\delta^{13} \mathrm{C}$ 范围为 $-50 \%$ - $65 \%$ ，而 $\mathrm{CO}_{2}$ 还原途 径产生的甲烷具有更负的 $\delta^{13} \mathrm{C}$ 值 $(-60 \% \text { - } 110 \% \text { o })^{[112]}$. 将特征性的脂类化合物以及较负的单体碳同位素值 相结合, 可以准确地识别地质历史时期甲烷氧化微 生物功能群.

一些特征性矿物也能提供这些微生物的活动记 录. 在海底冷泉喷口发育着高密度的化学自养微生 物群. 甲烷戻氧氧化过程形成的过饱和 $\mathrm{HCO}_{3}^{-}$, 能与 海水中的 $\mathrm{Ca}^{2+}$ 结合形成碳酸盐沉淀, 并形成凝块灰 岩、放射状和葡萄状文石胶结物，即冷泉碳酸盐. 冷 泉喷口形成的自生矿物还包括重晶石和石膏. 这些 自生矿物呈结壳状、丘状或似层状产于海底表面或近 表面, 厚度从数米到数十米不等 ${ }^{[113]}$. 过饱和的 $\mathrm{HS}$ 也能促进黄铁矿的沉淀，并常以草莓状形式出现. 与 天然气水合物有关的自生碳酸盐矿物具有明显偏负 的碳同位素组成，而重晶石的硫同位素则明显偏正. 
上述沉积构造和同位素组成特征可以帮助人们识别 地质历史时期的水合物释放事件，探讨这些事件对 地球环境及生态系统的影响. 典型的实例是我国三 峡地区陡山沱组的盖帽白云岩 ${ }^{[114,115]}$. 与冷泉不同的 是, 海底热液喷口形成的矿物以硫化物为主, 包括黄 铁矿、黄铜矿、磁黄铁矿、闪锌矿等. 含化石的块状 硫化物通常被看做是古海底黑烟图的残留物 ${ }^{[116]}$.

\section{3 与硫代谢相关的地质微生物功能群识别标志}

准确识别沉积记录中的各种硫代谢微生物功能 群是探讨地质历史时期硫循环及其相关的古海洋化 学的关键所在. 目前比较有效的手段有生物标志化 合物、铁化学、硫同位素等. 绿硫细菌(Chlorobiaceae) 和紫硫细菌 (Chromatiaceae) 是两类重要的利用硫化 氢进行厌氧代谢的微生物功能群, 能够很好地反映 地质历史上出现的硫化海洋. 这两类微生物都有特 殊的生物标志化合物. 前者主要有 chlorobactane, isorenieratane 和 2-烷基-1,3,4-三甲基苯. 后者主要是 okenan $\mathrm{e}^{[54]}$. 由于绿硫细菌的固碳途径是反三羧酸循 环，所合成的化合物往往具有很重的碳同位素组成， 因此, 2-烷基-1,3,4-三甲基苯或其他化合物(如法呢烷) 的碳同位素组成也是判断地质样品是否存在绿硫细菌 的一个主要手段. 硫酸盐还原细菌在现代环境中有比 较好的特征性化合物, 如高丰度的短链 $\left(\mathrm{C}_{15}, \mathrm{C}_{17}\right)$ 异构 和反异构脂肪酸 ${ }^{[17]}$. 然而这些化合物在成岩过程中, 很容易转换成更稳定也更普遍的异构和反异构烷烃, 从而失去了生物学意义. 目前, 在沉积岩中还没有很 好的指示硫酸盐还原细菌的生物标志化合物.

在硫酸盐还原过程中, 产生的大量硫化氢最终 转换成黄铁矿. 不同环境形成的黄铁矿, 其粒径有很 大的差别. 在非常缺氧环境, 硫酸盐还原作用发生在 水体中, 由于水中 $\mathrm{Fe}(\mathrm{II})$ 含量非常低, 所形成的黄铁 矿聚合体呈草莓状, 粒径非常小 $(4 \sim 5 \mu \mathrm{m})$, 且粒径分 布范围非常窄 ${ }^{[118]}$. 因此, 沉积物中草莓状黄铁矿的 粒径分布特征以及铁化学组成也是探讨地质历史时 期硫化海洋及其微生物功能群的一个重要手段 ${ }^{[119]}$.

在硫酸盐还原过程中, 硫同位素有明显的动力 学分馏, 形成的黄铁矿往往具有富轻同位素 $\left({ }^{32} \mathrm{~S}\right)$ 的 特征. 硫同位素组成也是探讨地质历史时期硫循环 及其微生物功能群的有效记录 ${ }^{[42]}$. 当海水硫酸盐浓 度非常低时, 形成的黄铁矿往往具有非常高的 $\delta^{34} \mathrm{~S}$ 值, 如前寒武纪的黄铁矿 ${ }^{[120]}$. 黄铁矿的硫同位素特
征还能反映当时海洋的氧化-还原界面. 当该界面位 于沉积物时, 形成的黄铁矿 $\delta^{34} \mathrm{~S}$ 值很高且变化范围 大. 随着分析技术的发展, 含量很低的 ${ }^{33} \mathrm{~S}$ 和 ${ }^{36} \mathrm{~S}$ 也能 够很精确地测定. 这些硫同位素能够很好地用来区 分古老沉积物中的硫酸盐还原功能群和硫的歧化功

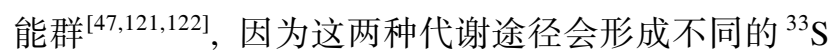
分馏系数.

\section{4 与氮代谢相关的地质微生物功能群识别标志}

识别沉积记录中与氮代谢相关的微生物功能群 是揭示地质历史时期氮循环过程的关键所在, 它只 能通过微生物膜脂和氮同位素等手段实现.一些固 氮蓝细菌, 如 Anabaena cylindrica 的异形胞中含有糖 脂化合物，由这类化合物形成的膜隔绝了氧气，使对 氧气敏感的固氮酶不受影响. 异形胞糖脂能够在地 层中保存较长时间而不降解, 可以作为示踪古海洋 蓝细菌固氮的标志物 ${ }^{[77]}$. 此外, 海洋中最主要的固 氮蓝细菌 Trichodesmium 能够合成独特的带 4 个羟基 侧链的不饱和蕓多醇, 可以作为示踪此类蓝细菌的 标志物 ${ }^{[123]}$.

氨氧化古菌的细胞膜脂拥有独特的含六元环的 泉古菌醇(crenarchaeol), 这类化合物甚至可以保存在 白严纪地层中 ${ }^{[124,125]}$. 海洋氨氧化泉古菌膜脂 (GDGTs)五元环数量与环境温度呈很好的正相关关 系，基于此建立的古温度指标 $\mathrm{TEX}_{86}$ 已经用于地史时 期古海洋表层海水温度的重建 ${ }^{[126]}$. 氨厌氧氧化细菌 的生物标志化合物梯烷 (ladderane), 主要来源于其结 构 annamoxsome 的膜脂, 起隔绝中间产物肼 $\left(\mathrm{NH}_{2} \mathrm{OH}\right)$ 进人细胞内的作用 ${ }^{[127]}$. 梯烷类化合物可应用于沉积 物氨厌氧氧化过程的示踪, 这也是目前唯一能够甄 别地质历史时期氨厌氧氧化细菌活动的方法 ${ }^{[128]}$.

除了地层中保存的这些特征性脂类化合物外, 氮同位素 $\delta^{15} \mathrm{~N}$ 也能够反映地质历史时期一些与氮循 环有关的微生物功能群及其作用. 蓝细菌固氮作用 能导致氮同位素分馏，使其合成的有机氮同位素在 $-3 \%$ 1 \%o的范围内变动. 固氮作用和非固氮作用所 产生的氮同位素具有一定的差异, 它在现代海洋潮 上带和潮间带微生物席中表现得较为明显. 潮上带 微生物席有机氮同位素明显比潮间带的偏负，并存 在固氮蓝细菌的标志物异形胞糖脂 ${ }^{[77]}$. 在白严纪大 洋缺氧时期和二叠纪-三叠纪生物大灭绝时期, 在沉 积地层中出现了有机氮 $\delta^{15} \mathrm{~N}$ 的负偏，显示了固氮蓝 


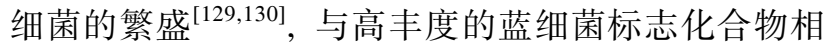
吻合 ${ }^{[131]}$. 微生物的固氮作用比其直接代谢 $\mathrm{NO}_{3}^{-}$要消 耗更多的能量, 即使是固氮蓝细菌也会优先利用 $\mathrm{NO}_{3}^{-}$作为氮源. 因此, 在一些重大地质突变时期, 海 洋蓝细菌固定大气氮作用的增强, 实际上间接地反

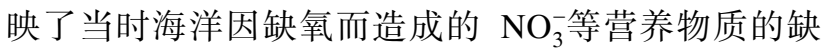
乏. 因此, $\delta^{15} \mathrm{~N}$ 记录的固氮蓝细菌的爆发很可能是响 应海洋缺氧事件和低 $\mathrm{NO}_{3}^{-}$浓度的结果。

反硝化作用(包括氨厌氧氧化作用)也能产生强 烈的氮同位素分馏，使残余的 $\mathrm{NO}_{3}^{-}$富集 ${ }^{15} \mathrm{~N}$. 藻类等 初级生产者利用这些富 ${ }^{15} \mathrm{~N}$ 的残余 $\mathrm{NO}_{3}^{-}$合成有机质时, 其 $\delta^{15} \mathrm{~N}$ 表现出较强的正值, 平均值为 $7 \%$ $9 \% 0^{[132]}$. 较高 $\delta^{15} \mathrm{~N}$ 值的出现可能与较强的反硝化作用有关. 较高的 $\delta^{15} \mathrm{~N}$ 值在间冰期表现得特别明显，间冰期冰 芯包裹体中的反硝化产物 $\mathrm{N}_{2} \mathrm{O}$ 浓度也较冰期的高, 此 时氮素大量转化为 $\mathrm{N}_{2}$, 最终导致海洋生产力的下降 ${ }^{[00]}$. 值得注意的是，通过对一些固氮蓝细菌的实验模拟， Bauersachs 等人 ${ }^{[77]}$ 发现 $\delta^{15} \mathrm{~N}$ 并不能将固氮作用与非 固氮作用(如直接利用 $\mathrm{NO}_{3}^{-}$)很好地区分开来, 两者相 对于氮源都可以表现出明显的 $\delta^{15} \mathrm{~N}$ 负偏. 此外, 微 生物对含氮有机质的降解、陆源有机质的输人和成岩 作用等都能够在一定程度上影响海洋有机氮的 $\delta^{15} \mathrm{~N}$ 值. 因此, $\delta^{15} \mathrm{~N}$ 应尽量结合更多的指标才能更好地解 译地质历史时期的氮循环.

\section{5 参与铁氧化还原的微生物功能群在地质体中 的识别标志}

铁氧化还原的微生物功能群难以在地质体中保 存, 即使保存下来的也难以从形态特征上加以识别. 一些分子特征, 如支链脂肪酸(如 10-甲基 $\mathrm{C}_{16: 0}$ ) 和异构 脂肪酸 (如 $i \mathrm{C}_{17: 1 \omega 7 \mathrm{c}}$ ), 被作为异化铁还原菌的标志化 合物, 但硫酸盐还原菌等微生物也能合成这些脂肪 酸 ${ }^{[133]}$. 尽管如此, 人们依据微生物代谢活动所形成 的含铁矿物特征，已经建立了一套逐渐认可的鉴别 标志, 包括矿物表征、组合及铁同位素特征等.

磁铁矿是微生物还原 $\mathrm{Fe}(\mathrm{III})$ 所产生的主要典型 矿物之一. 在自然界, 微生物诱导成因的磁铁矿, 虽 然很难从形态上与非生物成因的区别开来 ${ }^{[134]}$,但可 以从其他特征来区分. 通过把化学合成的与异化铁 还原菌 Shewanella oneidensis 诱导形成的磁铁矿进行 对比, Perez-Gonzalez 等人 ${ }^{[135]}$ 发现, 在 S. oneidensis 矿化过程中，细胞碎屑及代谢有机质与磁铁矿一起
沉淀，依据沉淀磁铁矿的热分解及红外光谱特征，提 出晶包有机质可作为磁铁矿生物成因的判别依据. 此外, 同化学合成的相比, 微生物异化还原所沉淀的 磁铁矿, 其结晶度较差 ${ }^{[135,136]}$, 含有过剩的 $\mathrm{Fe}^{2+}\left(\mathrm{Fe}^{2+}\right.$

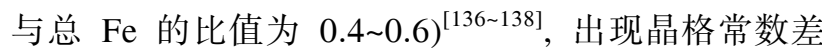
异 ${ }^{[136]}$ 和拉曼光谱振动吸收峰向高波段偏移 ${ }^{[135]}$ 等 特征.

除铁氧化物外, 黏土矿物结构 $\mathrm{Fe}(\mathrm{III})$ 也是铁还原 菌的有效电子受体 ${ }^{[139]}$. 黏土矿物被微生物还原的同 时释放出 $\mathrm{Si}$ 和 $\mathrm{Fe}$ 等元素, 在黏土矿物周围沉淀出无 定形 $\mathrm{SiO}_{2}$ 、二价铁矿物(如铁的硫化物矿物)、方解石 等次生矿物 ${ }^{[96,139]}$. 其中, 无定形 $\mathrm{SiO}_{2}$ 及铁的硫化物 可经成岩作用转变为石英及黄铁矿。因此, 依据矿物 组合特征(共生的含铁黏土矿物、石英、黄铁矿等), 并 结合其他指标(如硫同位素), 可大致推断该时期是否 存在铁还原微生物功能群 ${ }^{[140,141]}$.

近十年来, 利用铁同位素示踪微生物活动得到 了快速的发展和应用. 不产氧光合铁氧化菌形成的 水合氧化铁, 其 $\delta^{56} \mathrm{Fe}$ 比溶液 $\mathrm{Fe}(\mathrm{II})_{\mathrm{aq}}$ 的偏正约 $1.5 \%$, 这是由 $\mathrm{Fe}(\mathrm{III})_{\mathrm{aq}}$ 与 $\mathrm{Fe}(\mathrm{II})_{\mathrm{aq}}$ 之间的平衡分馏 $(2.9 \%)$ 以 及氧化铁与 $\mathrm{Fe}(\mathrm{III})_{\mathrm{aq}}$ 共沉淀的动力分馏 $(\sim-1.4 \%)$ 相叠 加造成的 ${ }^{[142,143]}$. 与之相比，硝酸盐还原菌形成的铁 氧化物, 其 $\delta^{56} \mathrm{Fe}$ 比溶液的高约 $3 \%$, 接近于常温下 $\mathrm{Fe}(\mathrm{III})_{\mathrm{aq}}$ 与 $\mathrm{Fe}(\mathrm{II})_{\mathrm{aq}}$ 之间的平衡分馏值 ${ }^{[144]}$. 异化铁还 原菌还原铁氧化物所产生的可溶 $\mathrm{Fe}(\mathrm{II})_{\mathrm{aq}}$, 其 $\delta^{56} \mathrm{Fe}$ 比 铁氧化物表面活性 $\mathrm{Fe}(\mathrm{IIII})$ 偏负约 $3 \%$ ，这可能是 $\mathrm{Fe}(\mathrm{II})_{\mathrm{aq}}$ 与铁氧化物表面活性 $\mathrm{Fe}(\mathrm{III})$ 通过电子传递及 原子交换所产生的分馏效应 ${ }^{[145]}$.

\section{4 微生物功能群的地质作用与重大地质环 境变化}

光合作用微生物功能群是地球上最重要的功能 群之一. 它的重要性主要体现在, 这些微生物功能群 大多能利用光能将 $\mathrm{CO}_{2}$ 转化为有机质, 通过碳循环 显著地影响地球环境. 同时, 产氧光合作用所产生的 氧气又进一步通过影响碳、硫、氮和铁等循环而改变 地球环境并影响其他生物的起源和演化. 光合作用 是行星地球由早期的无氧状态演化到富氧状态的主 要机制，也是后生生物能够出现的前提条件. 从某种 程度上来说, 光合作用微生物功能群是改变地球环 境的最重要的动力之一. 一些学者已经对光合作用 作了比较深人的论述 ${ }^{[14,146]}$, 本文不再重复. 
与碳循环有关的微生物功能群不仅影响海洋环 境, 更重要的是影响大气环境, 导致异常碳循环往往 与异常气候事件相伴, 而微生物的这些地质作用又 通过各种形式的有机质和无机矿物在地质体中记录 下来. 代谢硫的微生物功能群尽管也影响大气环境, 如现代海洋浮游微生物通过释放含硫有机化合物并 转变成二甲基硫对气候产生影响, 但在地质历史时 期, 要识别这一过程极其困难. 人们主要通过矿物的 硫同位素组成揭示这类微生物功能群对各种海洋环 境的影响. 代谢氮的微生物功能群则主要通过影响 地质环境的营养条件而影响其他生物, 并进而影响 环境，从而通过有机质的氮同位素记录其对地球环 境的影响.

需要指出的是, 在一些重大地质环境演化过程 中, 不同微生物功能群往往是协同作用的, 导致了多 种环境事件的同时出现. 例如, 在二叠纪-三叠纪之 交, 不仅出现了固氮微生物(蓝细菌)、硫代谢微生物 (绿硫细菌)和甲烷微生物(I 型甲烷氧化细菌)等各类 微生物功能群的大爆发, 而且出现了硫化海洋、低浓 度硫酸盐海洋、异常碳循环和气候事件, 以及生物大 灭绝等. 这不仅反映了一些关键微生物功能群的协 同作用, 而且微生物功能群与环境之间也是相互作 用的.

\section{1 地质微生物功能群与异常气候环境}

涉及碳循环核心的 $\mathrm{CO}_{2}$ 和 $\mathrm{CH}_{4}$ 等均是最重要的 温室气体, 异常碳循环的发生将直接与异常气候变 化(如冷、暖)相关连. 在地质历史时期, 与甲烷产生 和释放相关的微生物功能群的活动与全球气候变化 密切相关, 这些微生物单独或与其他生物协同作用, 使地质环境条件发生变化. 在泥炭环境, 甲烷氧化细 菌与泥炭藓共生 ${ }^{[147]}$. 这些甲烷氧化细菌将甲烷氧化 成 $\mathrm{CO}_{2}$, 供共生的泥炭藓进行光合作用. 这些与泥炭 藓共生的甲烷氧化细菌, 其多样性非常高 ${ }^{[148]}$. 这种 共生过程使得大量的甲烷能够在泥炭生态系统内部 进行循环, 减少了向大气的排放. 在北半球, 泥炭藓 覆盖的面积高达 $1.5 \times 10^{6} \mathrm{~km}^{2}$, 生物之间的这种协同 作用大大降低了泥炭地向大气排放 $\mathrm{CH}_{4}$ 的量 ${ }^{[149]}$. 然 而, 自末次冰期以来, 环北极地区泥炭湿地扩张速率 在距今 12 8 ka 达到峰值, 对应着大气甲烷浓度的急 剧增长阶段 ${ }^{[150,151]}$, 这还是说明了泥炭地甲烷释放对 大气甲烷的重要贡献.甲烷释放事件还与末次冰期
内部的暖事件有关 ${ }^{[152 ~ 154]}$. 不过, 近 $5 \mathrm{ka}$ 以来, 大气 甲烷浓度逐渐增高, 这可能不是由北半球泥炭地的 贡献造成的 ${ }^{[150,155]}$. 研究发现, 泥炭藓利用甲烷氧化 生成的 $\mathrm{CO}_{2}$ 占整个光合作用所固定 $\mathrm{CO}_{2}$ 的比例与水

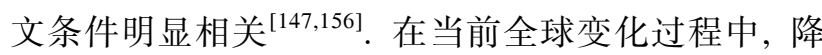
水量的变化将直接影响甲烷氧化细菌与泥炭藓的共 生关系, 进而影响到泥炭地甲烷的排放, 因而需要特 别的关注 ${ }^{[157]}$. 产甲烷和氧化甲烷微生物功能群对冰 期-间冰期旋回大气 $\mathrm{CO}_{2}$ 和 $\mathrm{CH}_{4}$ 浓度变化的贡献远未 查明.

在地质历史上, 紧接着大冰期出现了许多暖(或 高温)事件, 并伴随着大规模的海底天然气水合物释 放.一个鲜明的例子就是埃迪卡拉纪南沱冰期以后 出现的陡山沱暖期. 在华南已经发现了多处碳酸盐 碳同位素的极负值(可低至-48\%o), 可能存在着甲烷 的释放及其氧化过程 ${ }^{[15]}$, 虽然对这一解释目前还有 不同的认识 ${ }^{[158]}$. 发生在古新世与始新世界线附近 (55 Ma 前)的高温事件也特别引人注目. 在较短的时 间内(数千年), 大气温度上升 $5 \sim 9{ }^{\circ} \mathrm{C}^{[159,160]}$. 目前普遍 认可的起因是海洋甲烷水合物大量释放并被氧化所 造成的温室效应 ${ }^{[161,162]}$, 虽然一些研究者提出单靠二 氧化碳还难以解释这个时期的高温事件 ${ }^{[163]}$. Pancost 等人 ${ }^{[164]}$ 研究发现, 在该时期的陆上湿地, 出现了甲 烷氧化细菌的繁盛(来自细菌的蒦烷碳同位素出现了 非常明显的负偏). 这些工作均反映了微生物、甲烷 产生和释放、高温事件三者之间的内在成因联系，微 生物功能群通过调节甲烷来反馈(正反馈、负反馈)气 候事件. 中生代也发生了多次高温和高二氧化碳事 件, 如三叠系-侏罗系界线、侏罗纪早多尔斯阶与白 严纪早安普第阶, 其中的碳同位素显著负偏也被解 释为甲烷水合物释放造成的 ${ }^{[161]}$. 但微生物系统如何 响应和影响这些事件, 目前还了解得很少.

异常碳循环除了与重大气候变化相伴外, 还与 生物大灭绝事件(如二叠纪末期和白严纪末期等)紧 密相连 ${ }^{[165,166]}$. Stanley ${ }^{[167]}$ 提出, 造成显生宙多次生物 大灭绝期碳同位素突变的首要因素是海洋细菌呼吸 作用速率. 在这些生物大灭绝发生时, 大多伴随着全 球气候变化, 而温度的变化可以显著地改变微生物 的呼吸作用速率，进而影响具有较轻碳同位素值的 有机碳的埋藏量和海洋无机碳库的碳同位素值. 这 隐含着微生物、碳循环异常、气候变化、生物危机之 间的成因联系，但还有待于进一步证实. Luo 等人 ${ }^{[168]}$ 
发现，浙江煤山二叠纪-三叠纪界线剖面碳同位素偏 移对应着蓝细菌或绿硫细菌的大量繁盛, 认为宏体 生物灭绝之后微生物功能群的波动可以显著地影响 碳同位素分馏.

\section{2 地质微生物功能群与硫化海洋环境}

微生物繁盛产生大量的有机质, 这些有机质在 沉降矿化时消耗水体溶解氧而使水体出现缺氧的过 程早已经被人们所熟悉. 硫化海洋是指海水缺氧且 富含硫化氢的海洋环境. 地质历史上典型的硫化海 洋发生在晚前寒武纪. Canfield ${ }^{[169]}$ 认为, 从晚古元古 代到晚新元古代这段长达 10 多亿年的时间里, 海洋 是缺氧且富含硫化氢的，被称为“Canfield Ocean”. 这主要是由于地球早期随着大气氧含量的增加, 增 强的陆源风化作用使得输人海洋中的硫酸盐通量增 加, 从而导致海洋中的硫酸盐浓度增加. 硫酸盐的微 生物还原过程产生大量 $\mathrm{H}_{2} \mathrm{~S}$, 消耗海洋中的 $\mathrm{Fe}(\mathrm{II})$, 使早期富 $\mathrm{Fe}(\mathrm{II})$ 的海洋转化成富 $\mathrm{H}_{2} \mathrm{~S}$ 的海洋. 这个转 变时间发生在大约 18.4 亿年前 ${ }^{[170]}$. 在显生宙, 硫化 海洋也频繁地扰动正常海洋的沉积. 目前所知的几 个最主要的富硫化氢时期有晚寒武世 ${ }^{[171]}$ 、奥陶纪志留纪之交 ${ }^{[172]}$ 、晚泥盆世 ${ }^{[173]}$ 、二叠纪-三叠纪之 交 ${ }^{[55,174]}$ 以及白严纪的数次大洋缺氧时期 ${ }^{[175]}$ 等. 然而, 对于这些硫化海洋, 究竟是由盆地格局引起的区域 信息(如现代黑海)还是一个全球性的特征, 还有待于 进一步的研究.

在硫化海洋环境, 典型微生物功能群有硫酸盐 还原微生物、 $\mathrm{H}_{2} \mathrm{~S}$ 的厌氧氧化细菌和硫化物的好氧氧 化细菌. 具有硫酸盐还原功能的微生物主要是硫酸 盐还原细菌/古菌. 它们产生的大量 $\mathrm{H}_{2} \mathrm{~S}$, 是形成硫化 海洋的前提. 同时, 该过程使残余的硫酸盐硫同位素 逐渐正偏 ${ }^{[54,176]} . \mathrm{H}_{2} \mathrm{~S}$ 的厌氧氧化功能群为绿硫细菌和 紫硫细菌. 它们位于富 $\mathrm{H}_{2} \mathrm{~S}$ 的透光层, 把 $\mathrm{H}_{2} \mathrm{~S}$ 氧化成 硫酸盐 ${ }^{[54,55]}$. 硫化物的好氧氧化功能群与 $\mathrm{H}_{2} \mathrm{~S}$ 的厌氧 氧化功能群可能处于相同的位置, 前者也可能处于 更靠近水体表面的位置 ${ }^{[57]}$. 这些微生物功能群能形 成一些元素硫 ${ }^{[177]}$.

在硫化海洋, 还有一些微生物功能群具有反硝 化功能、氨的厌氧氧化功能和固氮功能 ${ }^{[178]}$. 前两类 微生物功能群能把绝大部分生物可利用的氮转换成 惰性氮气, 从而使海洋缺乏生物可利用的氮, 进而促 使以蓝细菌等为主的固氮微生物功能群的繁
盛 ${ }^{[178,179]}$. 另外, 在硫化海洋, 一些功能还未知的古 菌也占有重要的地位 ${ }^{[180,181]}$.

\section{3 地质微生物功能群与低浓度硫酸盐海洋环境}

硫酸盐浓度在现代海洋中是非常高的, 大约为 $29 \mathrm{mmol} / \mathrm{L}$ 左右. 但在地质历史上, 海水硫酸盐浓度 变化很大, 经常会出现海洋硫酸盐浓度非常低的时 期. 例如, 在前寒武纪的海洋, 硫酸盐浓度就非常 低 ${ }^{[44,182]}$. 在显生宙, 海水硫酸盐浓度也经历了较频 繁的波动 ${ }^{[183,184]}$, 在好几个时期出现异常低值, 如晚 寒武世至早泥盆世、二叠纪-三叠纪之交、三叠纪-侏 罗纪之交等 ${ }^{[176,185]}$.

产甲烷古菌是低浓度硫酸盐海洋的典型微生物 功能群之一. 产甲烷古菌和硫酸盐还原细菌都需要 氢气和乙酸盐进行代谢，它们之间就存在很大的竞 争 ${ }^{[186]}$. 当硫酸盐浓度降低时, 产甲烷古菌能够顺利 地获得氢气和乙酸盐 ${ }^{[54]}$, 从而出现繁盛. 同时, 因 $50 \%$ 以上的有机质是通过硫酸盐还原作用消耗的 ${ }^{[187]}$, 硫酸盐浓度的降低就会使更多的有机质进入甲烷生 成带, 从而也会促使产甲烷古菌的繁盛.

甲烷好氧氧化细菌是低浓度硫酸盐海洋的另一 典型微生物功能群. 产甲烷古菌的繁盛, 大大促进了 甲烷的生成通量. 同时, 由于这些甲烷的氧化是通过 甲烷戻氧氧化古菌与硫酸盐还原细菌的共生作用来 完成的 ${ }^{[35]}$, 而且 $80 \%$ 以上的甲烷氧化都是通过利用 硫酸盐作为电子受体完成的 ${ }^{[188]}$, 因此, 海洋硫酸盐 浓度的降低, 将大大减小甲烷的厌氧氧化通量. 这就 导致了甲烷好氧氧化细菌的繁盛. 典型的微生物包 括 3-甲基蕉烷所指示的 I 型甲烷氧化细菌，以及 II 型和 X 型甲烷氧化细菌. 现代的 I 型甲烷氧化细菌 主要出现在硫酸盐浓度低的湖相环境，而在硫酸盐 浓度较高的海相环境很少出现 ${ }^{[123]}$. 在前寒武纪, 特 别是晚太古代，I 型甲烷氧化细菌也非常繁盛，这与 当时海洋中极低的硫酸盐浓度相一致 ${ }^{[54,189]}$. 最近, 在二叠纪-三叠纪之交的地层中也发现了大量的 I 型 甲烷氧化细菌的生物标志化合物 ${ }^{[174]}$, 而且由碳酸盐 晶格的硫酸盐硫同位素反映出当时的海水硫酸盐浓 度也很低 ${ }^{[176]}$, 这进一步说明甲烷好氧氧化细菌是低 浓度硫酸盐海洋的典型微生物功能群. 综上所述, 在 低浓度硫酸盐海洋, 特征的微生物功能群主要是产 甲烷古菌和甲烷好氧氧化细菌, 当然也包括其他微 生物功能群, 如光合细菌等. 
上述分析表明，低浓度硫酸盐海洋的出现可能 会对地球环境和生物地球化学循环产生重要影响. 产甲烷代谢功能的盛行和甲烷厌氧氧化的减弱, 大 大增加了甲烷进人表层水体以及大气的通量.甲烷 进人大气之后所引起的温室效应将会导致大气温度 升高和风化作用加强, 从而引起海洋中营养盐和硫 酸盐浓度的增加, 和其他一系列生物地球化学作用 的变化. 目前, 对这些通量的定量/半定量分析还很 少, 这将是下一步研究工作的重点.

海洋硫酸盐在微生物地球化学循环过程中起着 非常重要的作用，而目前对地质历史时期海水硫酸 盐浓度了解得非常少. 前寒武纪的海水硫酸盐浓度 资料尤其缺乏, 即使有也存在很大的争议. 最新的研 究表明, 在古元古代末期和新元古代末期, 绝大部分 海洋还是富 $\mathrm{Fe}(\mathrm{II})$ 的, 只在局部发育一个很小的富 $\mathrm{H}_{2} \mathrm{~S}$ 的楔形水体 ${ }^{[190,191]}$, 说明当时海水硫酸盐浓度非 常低, 而且可能一直持续到晚寒武世 ${ }^{[192]}$. 然而我们 并不清楚在这两个时期海水硫酸盐浓度的演化特征, 以及这些低浓度硫酸盐海洋的形成机制.

\section{4 微生物功能群与地质营养条件}

自然界中的氮、磷、铁等是影响生物生长的重要 营养元素. 在浅海, 由地表径流和风尘所携带的陆源 营养元素常决定了海洋的营养条件. 在古新世-始新 世之交和二叠纪-三叠纪之交, 陆地风化作用的加剧, 使更多的陆源氮、磷、铁等营养元素输人海洋. 海洋 光合微生物功能群和固氮微生物功能群相对较为繁 盛, 出现了富营养化过程, 表现为一些光合藻类和以 蓝细菌为主的固氮微生物在丰度上明显增加, 并最 终导致有机质氮同位素负偏 ${ }^{[130,131,174]}$. 微生物功能群 既是地质环境营养条件改变的积极响应者, 同时又 能够影响和作用于海洋环境. 富营养化海洋的初级 生产者死亡后, 异养微生物对有机质的降解会耗尽 水体中的氧气, 使海洋水体缺氧. 相应地, 生存于透 光带缺氧层中的绿硫细菌和紫硫细菌能够繁盛 ${ }^{[174]}$, 同时反硝化作用会加强, 排放到大气中的温室气体 $\mathrm{N}_{2} \mathrm{O}$ 也会增加 ${ }^{[193]}$. 大量有机质沉积和较为缺氧的环 境可能为产甲烷古菌的繁盛提供条件, 加剧水体中 甲烷的释放 ${ }^{[194]}$. 这表明, 水体营养条件的变化能够 引发不同微生物功能群之间一系列的生物地球化学 作用, 从而显著地影响环境. 这些地质微生物功能群 的出现及其相关的海洋环境变化在二叠纪-三叠纪之
交表现得比较典型 ${ }^{[130,131,165,174]}$.

在远洋寡营养海区, 水体硝酸根比较缺乏, 固氮 蓝细菌通过固定大气 $\mathrm{N}_{2}$ 为生物提供了可利用的氮, 从而直接影响着海洋的初级生产力 ${ }^{[195]}$. 因而, 臭营 养条件下与氮相关的微生物功能群所驱动的氮循环 是决定海洋营养条件的关键因素. 据估算, 现代海洋 每年由生物固定的氮可达 $0.06 \times 10^{12} \sim 25 \times 10^{12} \mathrm{~mol}^{[196]}$. 这些氮成为维系海洋庞大食物链不可缺少的营养. 然而, 固氮微生物的固氮速率又受制于铁、锄和磷这 几种营养元素 ${ }^{[63,197,198]}$. 这些营养元素主要来自大气 风尘颗粒. 在冰期大气扬尘较大时, 粉尘携带至远洋 的 $\mathrm{Fe}$ 元素能够增加蓝细菌的固氮作用, 从而提升了 海洋初级生产力 ${ }^{[199]}$. 值得注意的是, 大气 $p \mathrm{CO}_{2}$ 的升 高尽管会使海水酸化, 降低古菌和细菌的氨氧化速 率, 但能使海洋蓝细菌固氮作用增强 ${ }^{[200]}$. 在二叠纪三叠纪之交, 大量的火山喷发导致大气 $p \mathrm{CO}_{2}$ 升高, 增加了海洋固氮蓝细菌在低硝酸盐环境与浮游藻类 的竞争能力 ${ }^{[201]}$. 同时, 海洋酸化能够降低硅藻和颗 石藻等浮游藻类获取溶解铁的能力, 使得铁对海洋 生产力的限制作用更为突出 ${ }^{[202]}$. 因此, 在大气 $p \mathrm{CO}_{2}$ 较高的地质时期, 固氮蓝细菌始终作为海洋中的主 要生产力, 对整个海洋生态系统产生重要的影响.

在地质历史时期的海洋中, 氮、磷等营养元素的 过剩往往会使某些地质微生物功能群大量繁盛, 并 最终可形成大规模的黑色岩系. 这些黑色岩系因富 含各类矿产资源和能源而具有很大的经济价值，同 时它们也是了解地质历史时期海水营养状况和化学 条件以及环境变化的重要窗口 ${ }^{[129,132,203]}$. 例如, 广泛 分布于扬子地台的下寒武统黑色页岩富含包括钼和镍 在内的多种金属元素和有机质.上升流带来的氮、磷 等营养元素促进以蓝细菌等为主的光合微生物功能 群的繁盛, 为黑色岩系贡献大量的有机质. 硫酸盐还 原菌在底层分层海水中的作用则很可能是 Mo 等多 种金属元素能够沉积并得以富集的重要原因 ${ }^{[204]}$. 因 而, 光合微生物功能群和硫代谢微生物功能群对黑 色岩系和多金属矿产等资源的形成可能起着非常关 键的作用. 黑色岩系地质微生物功能群的研究亟待 加强和突破.

\section{5 铁氧化还原微生物功能群与前寒武纪条带状 铁建造}

微生物参与铁的氧化及还原过程, 不仅仅是地 
表能量流的重要途径之一, 更与各类地质过程及其 环境变化密切相连, 如碳循环、生源元素运移、重金 属及核素的转化迁移等 ${ }^{[86,91]}$. 这里重点讨论其对前 寒武纪条带状铁建造的贡献.

广布于全球的前寒武纪条带状铁建造 (banded iron formation, 简称 BIFs), 是由硅质(燧石、石英等) 及铁质(磁铁矿、赤铁矿等)组成的具有韵律的海洋沉 积. BIFs 主要形成于 36 18 亿年前, 其中 25 亿年前为 其沉积高峰期 ${ }^{[205]}$. BIFs 形成时期的海水化学特征表 现为富 $\mathrm{Fe}^{2+}$ 而贫 $\mathrm{SO}_{4}^{2-}{ }^{206]}$. 因此, 在 BIFs 形成时期, 海水中丰富的 $\mathrm{Fe}^{2+}$ 是如何被大规模氧化而沉积为 $\mathrm{Fe}(\mathrm{III})$ 矿物的, 这是一个重要的科学问题. 目前, 有 3 种可能的机制. 一是蓝细菌光合作用产生的氧气氧 化水体中的 $\mathrm{Fe}^{2+}$. 但是, 在大气氧气浓度显著升高之 前(重大氧化事件 124.5 亿年前), 大气氧浓度仅为现 代的 $10^{-5} \sim 10^{-3}{ }^{[207]}$, 海水表层仅局部有氧 ${ }^{[87]}$. 即使在 24.5 18 亿年前, 大气氧气浓度也仅是现代大气的 0.02 0.04 倍, 海洋表现为表层充氧而深部缺氧的分 层现象 ${ }^{[207]}$. 因此, BIFs 主要是在缺氧水体中沉积的, 这排除了以蓝细菌为主体角色参与 BIFs 的形成 ${ }^{[208]}$. 第二种观点是紫外光驱动的光氧化反应, 但现代模 拟实验表明紫外光氧化不太可能成为 BIFs 沉积的主 因 ${ }^{[209]}$. 还有一种观点认为, 不产氧光合微生物在庈 氧水体中氧化 $\mathrm{Fe}^{2+}{ }^{[208]}$, 这突出了不产氧光合铁氧化 菌的重要性 ${ }^{[19,209]}$. 在北美 Gunflint 及 Biwabik BIFs 富铁叠层石中, 存在明显的负 $\mathrm{Ce}$ 异常及偏正的 $\delta^{56} \mathrm{Fe}$ 等特征, 确证了在 18.9 亿年前在浅海弱氧化环境存 在不产氧光合微生物的作用 ${ }^{[210]}$.

在 BIFs 时期, 大规模沉积的 $\mathrm{Fe}(\mathrm{III})$ 、深层水的 缺氧环境, 以及光合浮游微生物 (如不产氧光合铁氧
化菌)合成的有机物, 也为异养微生物提供了适宜的 环境条件 ${ }^{[87]}$. 在 25 亿年前澳大利亚 Hamersley 及南 非 Transvaal 的 BIFs 中, 存在负偏的 $\delta^{56} \mathrm{Fe}$, 这是异化 铁还原菌活动的证据 ${ }^{[143]}$. 最近, $\mathrm{Li}$ 等人 ${ }^{[211]}$ 根据共生 的磁铁矿及磷灰石、磁铁矿的晶格常数和穆斯堡尔谱, 以及有机质光谱特征等，进一步刻画了在 24.8 亿年 前的 BIFs 形成时期, 海洋出现了以光合浮游微生物 及异化还原菌为主体的微生物面貌.

\section{5 结论}

得益于对现代地质环境正在发生的微生物过程 的调查, 人们对与碳、硫、氮、铁等重要元素代谢和 循环有关的关键地质微生物功能群的特点已经有了 一定的了解. 结合对地质记录的研究, 人们已经认识 到, 一些微生物功能群(特别是与碳、氮、硫、铁等 元素的代谢和循环有关的)对地质历史时期的异常气 候、硫化海洋、低浓度硫酸盐海洋、地质营养条件以 及前寒武纪铁建造等方面起了重要作用. 然而, 地质 历史时期微生物的作用还远未查明，其主要的困难 在于大多数地质微生物不能像动物、植物那样可以从 形态和结构上开展分门别类的研究. 值得注意的是, 地质微生物因具有生理、生态和生物地球化学等功能 的多样性, 可以从功能群角度研究其对地质环境的 作用. 因而, 对地质历史时期微生物功能群的识别乃 是一个关键环节. 尽管在地质体中识别这些功能群 存在一些分子化石、地球化学、矿物学、沉积学等方 面的标志，但总体来说，这方面还很欠缺. 在当前的 研究背景下, 借助于生命科学领域的研究成果, 地质 微生物功能群应是人们突破生命与地质环境相互作 用的一个关键突破口.

\section{参考文献}

1 Morgan J P, Reston T J, Ranero C R. Contemporaneous mass extinctions, continental flood basalts, and "impact signals": Are mantle plume-induced lithospheric gas explosions the causal link? Earth Planet Sci Lett, 2004, 217: 263-284

3 谢树成, 龚一鸣, 童金南, 等. 从古生物学到地球生物学的跨越. 科学通报, 2006, 51: 2327-2336

4 殷鸿福, 谢树成, 童金南, 等. 谈地球生物学的重要意义. 古生物学报, 2009, 48: 293-301

5 谢树成, 殷鸿福, 史晓颖, 等. 地球生物学: 生命与地球环境的相互作用和协同演化. 北京: 科学出版社, 2011.63 
6 Kalyuzhnaya M G, Lapidus A, Ivanova N, et al. High-resolution metagenomics targets specific functional types in complex microbial communities. Nat Biotechnol, 2008, 26: 1029-1034

7 Strom S L. Microbial ecology of ocean biogeochemistry: A community perspective. Science, 2008, 320: 1043-1045

8 Falkowski P G, Fenchel T, Delong E F. The microbial engines that drive Earth's biogeochemical cycles. Science, 2008, 320: 1034-1039

9 Des Marais D J. When did photosynthesis emerge on earth? Science, 2000, 289: 1703-1705

10 Gray M W. The endosymbiont hypothesis revisited. Inter Rev Cytol, 1992, 141: 233-357

11 Buick R. The antiquity of oxygenic photosynthesis: Evidence from stromatolites in sulphate-deficient Archaean lakes. Science, 1992, 255: 74-77

12 Buick R. When did oxygenic photosynthesis evolve? Phil Trans R Soc B, 2008, 363: 2731-2734

13 Olson J M, Blankenship R. Thinking about the evolution of photosynthesis. Photosynth Res, 2004, 80: 373-386

14 Olson J M. Photosynthesis in the Archean Era. Photosynth Res, 2006, 88: 109-117

15 Xiong J, Fischer W M, Inoue K, et al. Molecular evidence for the early evolution of photosynthesis. Science, 2000, 289: 1724-1730

16 Widdel F, Schnell S, Heising S, et al. Ferrous iron oxidation by anoxygenic phototrophic bacteria. Nature, 1993, 362: 834-836

17 Ehrenreich A, Widdel F. Anaerobic oxidation of ferrous iron by purple bacteria, a new type of phototrophic metabolism. Appl Environ Microbiol, 1994, 60: 4517-4526

18 Heising S, Richter L, Ludwig W, et al. Chlorobium ferrooxidans sp. nov., a phototrophic green sulfur bacterium that oxidizes ferrous iron in coculture with a "Geospirillum" sp. strain. Arch Microbiol, 1999, 172: 116-124

19 Konhauser K O, Hamade T, Raiswell R, et al. Could bacteria have formed the Precambrian banded iron formations? Geology, 2002, 30: 1079-1082

20 Bekker A, Holland H D, Wang P L, et al. Dating the rise of atmospheric oxygen. Nature, 2004, 427: 117-120

21 Anbar A D, Duan Y, Lyons T W, et al. A whiff of oxygen before the Great Oxidation Event? Science, 2007, 317: $1903-1906$

22 Garvin J, Buick R, Anbar A D, et al. Isotopic evidence for an aerobic nitrogen cycle in the latest Archean. Science, 2009, 323: 1045-1048

23 Kaufman A J, Johnston D T, Farquhar J, et al. Late Archean biospheric oxygenation and atmospheric evolution. Science, 2007, 317 : 1900-1903

24 Catling D C, Claire M W. How Earth's atmosphere evolved to an oxic state: A status report. Earth Planet Sci Lett, 2005, 237: 1-20

25 Kopp R E, Kirschvink J L, Hiburn I A, et al. The Paleoproterozoic snowball earth: A climate disaster triggered by the evolution of oxygenic photosynthesis. Proc Natl Acad Sci USA, 2005, 102: 11131-11136

26 Ohmoto H. When did the Earth's atmosphere become oxic? Geochem News, 1997, 93: 26-27

27 Knoll A H, Summons R E, Waldbauer J R, et al. The geological succession of primary producers in the oceans. In: Falkowski P G, Knoll A H, eds. Evolution of Primary Producers in the Sea. Burlington: Elsevier Academic Press, 2007. 133-163

28 Jiao N Z, Herndl G J, Hansell D A, et al. Microbial production of recalcitrant dissolved organic matter: Long-term carbon storage in the global ocean. Nat Rev Microbiol, 2010, 8: 593-599

29 Mittere R M. Methanogenesis and sulfate reduction in marine sediments: A new model. Earth Planet Sci Lett, 2010, 295: 358-366

30 Yoshioka H, Maruyama A, Nakamura T, et al. Activities and distribution of methanogenic and methane-oxidizing microbes in marine sediments from the Cascadia Margin. Geobiology, 2010, 8: 223-233

31 Eriksson T, Öquist M G, Nilsson M B. Production and oxidation of methane in a boreal mire after a decade of increased temperature and nitrogen and sulfur deposition. Glob Change Biol, 2010, 16: 2130-2144

32 Shoemaker J K, Schrag D P. Subsurface characterization of methane production and oxidation from a New Hampshire wetland. Geobiology, 2010, 8: 234-243

33 Martinson G O, Werner F A, Sherber C, et al. Methane emissions from tank bromeliads in neotropical forests. Nat Geosci, 2010, 3: 1-4

34 Boetius A, Ravenschlag K, Schubert C J, et al. A marine microbial consortium apparently mediating anaerobic oxidation of methane. Nature, 2000, 407: 623-626

35 Orphan V J, House C H, Hinrichs K U, et al. Methane-consuming Archaea revealed by directly coupled isotopic and phylogenetic analysis. Science, 2001, 293: 484-487

36 Hallam S J, Putnam N, Preston C M, et al. Reverse methanogenesis: Testing the hypothesis with environmental genomics. Science, 2004, 305: $1457-1462$

37 Raghoebarsing A A, Pol A, van de Pas-Schoonen K T, et al. A microbial consortium couples anaerobic methane oxidation to denitrification. Nature, 2006, 440: 918-921

38 Ettwig K F, Butler M K, Paslier D L, et al. Nitrite-driven anaerobic methane oxidation by oxygenic bacteria. Nature, 2010, 464: 543-548

39 Dunfield P F, Yuryev A, Senin P, et al. Methane oxidation by an extremely acidophilic bacterium of the phylum Verrucomicrobia. Nature, 2007, 450: 879-882 
40 Stetter K O. Hyperthermophilic procaryotes. FEMS Microbiol Rev, 1996, 18: 149-158

41 Rabus A, Hansen T A, Widdel F. Dissimilatory sulfate- and sulfur-reducing prokaryotes. In: Dworkin M, Falkow S, Rosenberg E, et al, eds. The Prokaryotes. New York: Springer, 2006. 659-768

42 Shen Y A, Buick R, Canfield D E. Isotopic evidence for microbial sulphate reduction in the early Archaean era. Nature, 2001, 410: 77-81

43 Shen Y A, Farquhar J, Masterson A, et al. Evaluating the role of microbial sulfate reduction in the early Archean using quadruple isotope systematics. Earth Planet Sci Lett, 2009, 279: 383-391

44 Habicht K S, Gade M, Thamdrup B, et al. Calibration of sulfate levels in the Archean ocean. Science, 2002, 298: 2372-2374

45 Thamdrup B, Finster K, Hansen J W, et al. Bacterial disproportionation of elemental sulfur coupled to chemical reduction of iron and manganese. Appl Environ Microbiol, 1993, 59: 101-108

46 Canfield D E, Thamdrup B. The production of ${ }^{34} \mathrm{~S}$ depleted sulfide during bacterial disproportionation of elemental sulfur. Science, 1994, 266: $1973-1975$

47 Johnston D T, Wing B A, Farquhar J, et al. Active microbial sulfur disproportionation in the Mesoproterozoic. Science, 2005, 310: 1477-1479

48 Parnell J, Boyce A J, Mark D, et al. Early oxygenation of the terrestrial environment during the Mesoproterozoic. Nature, 2010, 468: 290-293

49 Wacey D, McLoughlin N, Whitehouse M J, et al. Two coexisting sulfur metabolisms in a ca. 3400 Ma sandstone. Geology, 2010, 38: 1115-1118

50 Canfield D E, Farquhar J, Zerkle A L. High isotope fractionations during sulfate reduction in a low-sulfate euxinic ocean analog. Geology, 2010, 38: 415-418

51 Wortmann U G, Bernasconi S M, Bottcher M E. Hypersulfidic deep biosphere indicates extreme sulfur isotope fractionation during single-step microbial sulfate reduction. Geology, 2001, 29: 647-650

52 Sim M S, Bosak T, Ono S H. Large sulfur isotope fractionation does not require disproportionation. Science, 2011, 333: 74-78

53 Canfield D E, Teske A. Late proterozoic rise in atmospheric oxygen concentration inferred from phylogenetic and sulphur-isotope studies. Nature, 1996, 382: 127-132

54 Brocks J J, Love G D, Summons R E, et al. Biomarker evidence for green and purple sulphur bacteria in a stratified Palaeoproterozoic sea. Nature, 2005, 437: 866-870

55 Grice K, Cao C, Love G D, et al. Photic zone euxinia during the Permian-Triassic superanoxic event. Science, 2005, 307: 706-709

56 Logan G A, Hinman M C, Walter M R, et al. Biogeochemistry of the 1640 Ma McArthur River (HYC) lead-zinc ore and host sediments, Northern Territory, Australia. Geochim Cosmochim Acta, 2001, 65: 2317-2336

57 Wakeham S G, Amann R, Freeman K H, et al. Microbial ecology of the stratified water column of the Black Sea as revealed by a comprehensive biomarker study. Org Geochem, 2007, 38: 2070-2097

58 Sorokin D Y. Diversity of halophilic sulfur-oxidizing bacteria in hypersaline habitats. In: Dahl C, Friedrich C G, eds. Microbial Sulfur Metabolism. Berlin: Springer, 2008. 225-237

59 Wacey D, Saunders M, Brasier M D, et al. Earliest microbially mediated pyrite oxidation in $~ 3.4$ billion-year-old sediments. Earth Planet Sci Lett, 2011, 301: 393-402

60 Gruber N, Galloway J N. An Earth-system perspective of the global nitrogen cycle. Nature, 2008, 451: 293-296

61 Moisander P H, Beinart R A, Hewson I, et al. Unicellular cyanobacterial distributions broaden the oceanic $\mathrm{N}_{2}$ fixation domain. Science, 2010, 327: 1512-1514

62 Zehr J P, Jenkins B D, Short S M, et al. Nitrogenase gene diversity and microbial community structure: A cross-system comparison. Environ Microbiol, 2003, 5: 539-554

63 Barron A R, Wurzburger N, Bellenger J P, et al. Molybdenum limitation of asymbiotic nitrogen fixation in tropical forest soils. Nat Geosci, 2009, 2: 42-45

64 Severin I, Acinas S G, Stal L J. Diversity of nitrogen-fixing bacteria in cyanobacterial mats. FEMS Microbiol Ecol, 2010, 73: 514-525

65 Prosser J I, Nicol G W. Relative contributions of archaea and bacteria to aerobic ammonia oxidation in the environment. Environ Microbiol, 2008, 10: 2931-2941

66 Leininger S, Urich T, Schloter M, et al. Archaea predominate among ammonia-oxidizing prokaryotes in soils. Nature, 2006, 442: 806-809

67 Francis C A, Roberts K J, Beman J M, et al. Ubiquity and diversity of ammonia-oxidizing archaea in water columns and sediments of the ocean. Proc Natl Acad Sci USA, 2005, 102: 14683-14688

68 Zhang L M, Offre P R, He J Z, et al. Autotrophic ammonia oxidation by soil thaumarchaea. Proc Natl Acad Sci USA, 2010, 107: $17240-17245$

69 Pratscher J, Dumont M G, Conrad R. Ammonia oxidation coupled to $\mathrm{CO}_{2}$ fixation by archaea and bacteria in an agricultural soil. Proc Natl Acad Sci USA, 2011, 108: 4170-4175 
70 Martens-Habbena W, Berube P M, Urakawa H, et al. Ammonia oxidation kinetics determine niche separation of nitrifying Archaea and Bacteria. Nature, 2009, 461: 976-979

71 Beman J M, Chow C E, King A L, et al. Global declines in oceanic nitrification rates as a consequence of ocean acidification. Proc Natl Acad Sci USA, 2011, 108: 208-213

72 Risgaard-Petersen N, Langezaal A M, Ingvardsen S, et al. Evidence for complete denitrification in a benthic foraminifer. Nature, 2006, 443: 93-96

73 Codispoti L A. An oceanic fixed nitrogen sink exceeding $400 \mathrm{Tg} \mathrm{Na}^{-1}$ vs the concept of homeostasis in the fixed-nitrogen inventory. Biogeosciences, 2007, 4: 233-253

74 Kuypers M M M, Lavik G, Thamdrup B. Anaerobic ammonium oxidation in the marine environment. In: Neretin L, ed. Past and Present Water Column Anoxia. Dordrecht: Springer, 2006. 311-335

75 Francis C A, Beman J M, Kuypers M M M. New processes and players in the nitrogen cycle: The microbial ecology of anaerobic and archaeal ammonia oxidation. ISME J, 2007, 1: 19-27

76 Li H, Chen S, Mu B Z, et al. Molecular detection of anaerobic ammonium-oxidizing (anammox) bacteria in high-temperature petroleum reservoirs. Microb Ecol, 2010, 60: 771-783

77 Bauersachs T, Speelman E N, Hopmans E C, et al. Fossilized glycolipids reveal past oceanic $\mathrm{N}_{2}$ fixation by heterocystous cyanobacteria Proc Natl Acad Sci USA, 2010, 107: 19190-19194

78 Frei R, Gaucher C, Poulton S W, et al. Fluctuations in Precambrian atmospheric oxygenation recorded by chromium isotopes. Nature, 2009, 461: 250-253

79 Blankenship R, Madigan M, Bauer C. Microbiology of nitrogen fixation by anoxygenic photosynthetic bacteria. In: Govindjee J, Amesz J, Barber R E, et al, eds. Anoxygenic Photosynthetic Bacteria, 2, Advances in Photosynthesis and Respiration. Netherlands: Springer, 2004. 915-928

80 Raymond J, Siefert J L, Staples C R, et al. The natural history of nitrogen fixation. Mol Biol Evol, 2004, 21: 541-554

81 Thomazo C, Ader M, Philippot P. Extreme ${ }^{15} \mathrm{~N}$-enrichments in 2.72-Gyr-old sediments: Evidence for a turning point in the nitrogen cycle. Geobiology, 2011, 9: 107-120

82 Byrne N, Strous M, Crepeau V, et al. Presence and activity of anaerobic ammonium-oxidizing bacteria at deep-sea hydrothermal vents ISME J, 2009, 3: 117-123

83 Zerkle A L, House C H, Cox R P, et al. Metal limitation of cyanobacterial $\mathrm{N}_{2}$ fixation and implications for the Precambrian nitrogen cycle. Geobiology, 2006, 4: 285-297

84 Bazylinski D A, Frankel R B. Magnetosome formation in prokaryotes. Nat Rev Microbiol, 2004, 2: 217-230

85 潘永信, 邓成龙, 刘青松, 等. 趋磁细菌磁小体的生物矿化作用和磁学性质研究进展. 科学通报, 2004, 49: 2505-2510

86 Weber K A, Achenbach L A, Coates J D. Microorganisms pumping iron: Anaerobic microbial iron oxidation and reduction. Nat Rev Microbiol, 2006, 4: 752-764

87 Konhauser K O, Kappler A, Roden E E. Iron in microbial metabolisms. Elements, 2011, 7: 89-93

88 Kappler A, Newman D K. Formation of Fe(III)-minerals by Fe(II)-oxidizing photoautotrophic bacteria. Geochim Cosmochim Acta, 2004, 68: $1217-1226$

89 Kappler A, Pasquero C, Konhauser K O, et al. Deposition of banded iron formations by anoxygenic phototrophic Fe(II)-oxidizing bacteria Geology, 2005, 33: 865-868

90 Miot J, Benzerara K, Morin G, et al. Transformation of vivianite by anaerobic nitrate-reducing iron-oxidizing bacteria. Geobiology, 2009, 7: $373-384$

91 Lovley D R, Holmes D E, Neivn K P. Dissimilatory Fe(III) and Mn(IV) reduction. Adv Microb Physiol, 2004, 49: 219-286

92 Lovley D R, Stolz J F, Nord G L, et al. Anaerobic production of magnetite by a dissimilatory iron-reducing microorganism. Nature, 1987, 330: $252-254$

93 Myers C R, Nealson K H. Bacterial manganese reduction and growth with manganese oxide as the sole electron acceptor. Science, 1988, 240: 1319-1321

94 Lehours A, Rabiet M, Morel-Desrosiers N, et al. Ferric iron reduction by fermentation strain BS2 isolated from an iron-rich anoxic environmental (Lake Pavin, France). Geomicrobiol J, 2010, 27: 714-722

95 Coleman M L, Hedrick D B, Lovley D R, et al. Reduction of Fe(III) in sediments by sulfate reducing bacteria. Nature, 1993, 361: 436-438

96 Li Y, Vali H, Sears S K, et al. Iron reduction and alteration of nontronite NAu-2 by a sulfate-reducing bacterium. Geochim Cosmochim Acta, 2004, 68: 3251-3260

97 Bond D R, Lovley D R. Reduction of Fe(III) oxide by methanogens in the presence and absence of extracellular quinones. Environ Microbiol, 2002, 4: 115-124 
98 Liu D, Dong H, Bishop M E, et al. Reduction of structural Fe(III) in nontronite by methanogen Methanosarcina barkeri. Geochim Cosmochim Acta, 2011, 75: 1057-1071

99 Vargas M, Kashefi K, Blunt-Harris E L, et al. Microbiological evidence for Fe(III) reduction on early Earth. Nature, 1998, 395: 65-67

100 Schrenk M O, Edwards K J, Goodman R M, et al. Distribution of Thiobacillus ferrooxidans and Leptospirillum ferroxidans: Implications for generation of acid mine drainage. Science, 1998, 279: 1519-1522

101 Coupland K, Johnson D B. Evidence that the potential for dissimilatory ferric reduction is widespread among acidophilic heterotrophic bacteria. FEMS Microbiol Lett, 2008, 279: 30-35

102 Summons R E, Jahnke L L, Hope J M, et al. 2-Methylhopanoids as biomarkers for cyanobacterial oxygenic photosynt hesis. Nature, 1999, 400: $554-557$

103 Köster J, Volkman J K, Rullkötter J, et al. Mono-, di- and trimethyl-branched alkanes in cultures of the filamentous cyanobacterium Calothrix scopulorum. Org Geochem, 1999, 30: 1367-1379

104 Grice K, Schaeffer P, Schwark L, et al. Molecular indicators of palaeoenvironmental conditions in an immature Permian shale (Kupferschiefer, Lower Rhine Basin, N.W. Germany) from free and S-bound lipids. Org Geochem, 1996, 25: 131-147

105 Summons R E, Powell T G. Chlorobiaceae in Palaeozoic sea revealed by biological markers, isotopes and geology. Nature, 1986, 319 : $763-765$

106 Sinninghe Damsté J S, Muyzer G, Abbas B, et al. The rise of the rhizosolenid diatoms. Science, 2004, 304: 584-588

107 Holba A G, Tegelaar E W, Huizinga B J, et al. 24-norcholestanes as age-sensitive molecular fossils. Geology, 1998, 26: 783-786

108 Bianchi T S, Canuel E A. Chemical Biomarkers in Aquatic Ecosystems. Princeton and Oxford: Princeton University Press, 2011

109 Niemann H, Lösekann T, de Beer D, et al. Novel microbial communities of the Haakon Mosby mud volcano and their role as a methane sink. Nature, 2006, 443: 854-858

110 Blumenberg M, Seifert R, Reitner J, et al. Membrane lipid patterns typify distinct anaerobic methanotrophic consortia. Proc Natl Acad Sci USA, 2004, 101: 11111-11116

111 Cvejic J H, Bodrossy L, Kovács K L, et al. Bacterial triterpenoids of the hopane series from the methanotrophic bacteria Methylocaldum spp: Phylogenetic implications and first evidence for an unsaturated aminobacteriohopanepolyol. FEMS Microbiol Lett, 2000, 182: 361-365

112 Whitcar M J, Faber E, Schoell M. Biogenic methane formation in marine and freshwater environments: $\mathrm{CO}_{2}$ reduction vs. acetate fermentation-isotope evidence. Geochim Cosmochim Acta, 1986, 50: 693-709

113 Conti S, Artoni A, Piola G. Seep-carbonates in a thrust-related anticline at the leading edge of an orogenic wedge: The case of the middle-late Miocene Salsomaggiore Ridge (Northern Apennines, Italy). Sediment Geol, 2007, 199: 233-251

114 Jiang G Q, Kennedy M J, Christie-Blick N. Stable isotopic evidence for methane seeps in Neoproterozoic postglacial cap carbonates. Nature, 2003, 426: 822-826

115 Wang J S, Jiang G Q, Xiao S H, et al. Carbon isotope evidence for widespread methane seeps in the ca. 635 Ma Doushantuo cap carbonate in south China. Geology, 2008, 36: 347-350

116 Rasmussen B. Filamentous microfossils in a 3235-million-year-old volcanogenic massive sulphide deposit. Nature, 2000, 405: 676-679

117 Zhang C L, Li Y L, Wall J D, et al. Lipid and carbon isotopic evidence of methane-oxidizing and sulfate-reducing bacteria in association with gas hydrates from the Gulf of Mexico. Geology, 2002, 30: 239-242

118 Wilkin R T, Barnes H L. Formation processes of framboidal pyrite. Geochim Cosmochim Acta, 1997, 61: 323-339

119 Wilkin R T, Arthur M A, Dean W E. History of water-column anoxia in the Black Sea indicated by pyrite framboid size distributions. Earth Planet Sci Lett, 1997, 148: 517-525

120 Sarkar A, Chakraborty P P, Mishra B, et al. Mesoproterozoic sulphidic ocean, delayed oxygenation and evolution of early life: Sulphur isotope clues from Indian Proterozoic basins. Geol Magaz, 2010, 147: 206-218

121 Farquhar J, Johnston D T, Wing B A, et al. Multiple sulphur isotopic interpretations of biosynthetic pathways: Implications for biological signatures in the sulphur isotope record. Geobiology, 2003, 1: 27-36

122 Johnston D T, Farquhar J, Wing B A, et al. Multiple sulfur isotope fractionations in biological systems: A case study with sulfate reducers and sulfur disproportionators. Am J Sci, 2005, 305: 645-660

123 Talbot H M, Summons R E, Jahnke L L, et al. Cyanobacterial bacteriohopanepolyol signatures from cultures and natural environmental settings. Org Geochem, 2008, 39: 232-263

124 Kuypers M M M, Blokker P, Erbacher J, et al. Massive expansion of marine archaea during a mid-Cretaceous oceanic anoxic event. Science, 2001, 293: 92-94

125 Sinninghe Damsté J S, Schouten S, Hopmans E C, et al. Crenarchaeol: The characteristic core glycerol dibiphytanyl glycerol tetraether membrane lipid of cosmopolitan pelagic crenarchaeota. J Lipid Res, 2002, 43: 1641-1651 
126 Liu Z H, Pagani M, Zinniker D, et al. Global cooling during the Eocene-Oligocene climate transition. Science, 2009, 323: 1187-1190

127 Sinninghe Damsté J S, Strous M, Rijpstra W I C, et al. Linearly concatenated cyclobutane lipids form a dense bacterial membrane. Nature, 2002, 419: 708-712

128 Jaeschke A, Ziegler M, Hopmans E C. et al, Molecular fossil evidence for anaerobic ammonium oxidation in the Arabian Sea over the last glacial cycle. Paleoceanography, 2009, 24: PA2202

129 Kuypers M M M, van Breugel Y, Schouten S, et al. $\mathrm{N}_{2}$-fixing cyanobacteria supplied nutrient N for Cretaceous oceanic anoxic events Geology, 2004, 32: 853-856

130 Luo G, Wang Y, Algeo T J, et al. Enhanced nitrogen fixation in the immediate aftermath of the latest Permian marine mass extinction. Geology, 2011, 39: 647-650

131 Xie S, Pancost R D, Yin H, et al. Two episodes of microbial change coupled with Permo/Triassic faunal mass extinction. Nature, 2005, 434: 494-497

132 Meyers P A, Bernasconi S M, Yum J G. 20 m.y. of nitrogen fixation during deposition of mid-Cretaceous black shales on the Demerara Rise, equatorial Atlantic Ocean. Org Geochem, 2009, 40: 158-166

133 Zhang C L, Li Y, Ye Q, et al. Carbon isotope signatures of fatty acids in Geobacter metallireducens and Shewanella algae. Chem Geol, 2003, 195: 17-28

134 Bazylinski D A, Schübbe S. Controlled biomineralization by and applications of magnetotactic bacteria. Adv Appl Microbiol, 2007, 62: 21-62

135 Perez-Gonzalez T, Jimenez-Lopez C, Neal A L, et al. Magnetite biomineralization induced by Shewanella oneidensis. Geochim Cosmochim Acta, 2010, 74: 967-979

136 Li Y, Pfiffner S M, Dyar M D, et al. Degeneration of biogenic superparamagnetic magnetite. Geobiology, 2009, 7: 25-34

137 Kukkadapu R K, Zachara J M, Fredrickson J K, et al. Ferrous hydroxyl carbonate is a stable transformation product of biogenic magnetite. Am Mineral, 2005, 90: 510-515

138 Carvallo C, Sainctavit P, Arrio M, et al. Biogenic vs. abiogenic magnetite nanoparticles: A XMCD study. Am Mineral, 2008, 93: 880-885

139 Dong H, Jaisi D P, Kim J, et al. Microbe-clay mineral interactions. Am Mineral, 2009, 94: 1505-1519

140 Vorhies J S, Gaines R R. Microbial dissolution of clay minerals as source of iron and silica in marine sediments. Nat Geosci, 2009, 2: $221-225$

141 Sanz-Montero M, Rodriguez-Aranda J P, Pérez-Soba C. Microbial weathering of Fe-rich phyllosilicates and formation of pyrite in the dolomite precipitating environment of a Miocene lacustrine system. Eur J Mineral, 2009, 21: 163-175

142 Croal L R, Johnson C M, Beard B L, et al. Iron isotope fractionation by Fe(II)-oxidizing photoautotrophic bacteria. Geochim Cosmochim Acta, 2004, 68: 1227-1242

143 Johnson C M, Beard B L, Klein C, et al. Iron isotopes constrain biologic and abiologic processes in banded iron formation genesis. Geochim Cosmochim Acta, 2008, 72: 151-169

144 Kappler A, Johnson C M, Croby H A, et al. Evidence for equilibrium iron isotope fractionation by nitrate-reducing iron( II )-oxidizing bacteria. Geochim Cosmochim Acta, 2010, 74: 2826-2842

145 Crosby H A, Johnson C M, Roden E E, et al. Coupled Fe(II)-Fe(III) electron and atom exchange as a mechanism for Fe isotope fractionation during dissimilatory iron oxide reduction. Environ Sci Technol, 2005, 39: 6698-6704

146 Grzebyk D, Schofield O, Vetriani C, et al. The Mesozoic radiation of Eukaryotic algae: The portable plastid hypothesis. J Phycol, 2003, 39: $259-267$

147 Raghoebarsing A A, Smolders A J P, Schmid M C, et al. Methanotrophic symbionts provide carbon for photosynthesis in peat bogs. Nature, 2005, 436: 1153-1156

148 Kip N, van Winden J F, Pan Y, et al. Global prevalence of methane oxidation by symbiotic bacteria in peat-moss ecosystems. Nat Geosci, 2010, 3: 617-621

149 Rydin H, Gunnarsson U, Sundberg S. The role of Sphagnum in peatland development and persistence. In: Wieder R K, Vitt D H, eds. Boreal Peatland Ecosystems. New York: Springer, 2006. 47

150 MacDonald G M, Beilman D W, Kremenetski K V, et al. Rapid early development of circumarctic peatlands and atmospheric $\mathrm{CH}_{4}$ and $\mathrm{CO}_{2}$ variations. Science, 2006, 314: 285-288

151 Jones M C, Yu Z C. Rapid deglacial and early Holocene expansion of peatlands in Alaska. Proc Natl Acad Sci USA, 2010, 107: 7347-7352

152 Kennett J P, Cannariato K G, Hendy I L, et al. Carbon isotopic evidence for methane hydrate instability during Quaternary interstadials. Science, 2000, 288: 128-133

153 Hinrichs K U, Hmelo L R, Sylva S P. Molecular fossil record of elevated methane levels in Late Pleistocene coastal waters. Science, 2003, 299: 1214-1217 
154 de Garidel-Thoron T, Beaufort L, Bassinot F, et al. Evidence for large methane releases to the atmosphere from deep-sea gas-hydrate dissociation during the last glacial episode. Proc Natl Acad Sci USA, 2004, 101: 9187-9192

155 Ruddiman W F, Guo Z T, Zhou X, et al. Early rice farming and anomalous methane trends. Quat Sci Rev, 2008, 27: 1291-1295

156 van Winden J F, Kip N, Reichart G-J, et al. Lipids of symbiotic methane-oxidizing bacteria in peat moss studied using stable carbon isotope labeling. Org Geochem, 2010, 41: 1040-1044

157 Chen Y, Murrell J C. Geomicrobiology: Methanotrophs in moss. Nat Geosci, 2010, 3: 595-596

158 Bristow T F, Bonifacie M, Derkowsk A, et al. A hydrothermal origin for isotopically anomalous cap dolostone cements from south China. Nature, 2011, 474: 68-71

159 Tripati A, Elderfield H. Deep-sea temperature and circulation changes at the Paleocene-Eocene Thermal Maximum. Science, 2005, 308: 1894-1898

160 Sluijs A, Schouten S, Pagani M, et al. Subtropical Arctic Ocean temperatures during the Palaeocene/Eocene Thermal Maximum. Nature, 2006, 441: 610-613

161 Jenkyns H C. Evidence for rapid climate change in the Mesozoic-Palaeogene greenhouse world. Phil Trans R Soc Lond A, 2003, 361: 1885-1916

162 Pagani M, Calderia K, Archer D, et al. An ancient carbon mystery. Science, 2006, 314: 1556-1557

163 Zeebe R E, Zachos J C, Dickens G R. Carbon dioxide foring alone insufficient to explain Palaeocene-Eocene Thermal Maximum warming. Nat Geosci, 2009, 2: 1-5

164 Pancost R D, Steart D S, Handley L, et al. Increased terrestrial methane cycling at the Palaeocene-Eocene thermal maximum. Nature, 2007, 449: 232-235

165 Xie S, Pancost R D, Huang J, et al. Changes in the global carbon cycle occurred as two episodes during the Permian-Triassic crisis. Geology, 2007, 35: 1083-1086

166 Wignall P B, Sun Y D, Bond D P G, et al. Volcanism, mass extinction, and carbon isotope fluctuations in the Middle Permian of China. Science, 2009, 324: 1179-1182

167 Stanley S M. Relation of Phanerozoic stable isotope excursions to climate, bacterial metabolism, and major extinctions. Proc Natl Acad Sci USA, 2010, 107: 19185-19189

168 Luo G, Huang J, Xie S, et al. Relationships between carbon isotope evolution and variation of microbes during the Permian-Triassic transition at Meishan Section, South China. Int J Earth Sci, 2010, 99: 775-784

169 Canfield D E. A new model for Proterozoic ocean chemistry. Nature, 1998, 396: 450-453

170 Poulton S W, Fralick P W, Canfield D E. The transition to a sulphidic ocean 1.84 billion years ago. Nature, 2004, 431: 173-177

171 Gill B C, Lyons T W, Young S A, et al. Geochemical evidence for widespread euxinia in the Later Cambrian ocean. Nature, 2011, 469: 80-83

172 Armstrong H A, Abbott G D, Turner B R, et al. Black shale deposition in an Upper Ordovician-Silurian permanently stratified, peri-glacial basin, southern Jordan. Palaeogeogr Palaeoclima Palaeoecol, 2009, 273: 368-377

173 Marynowski L, Filipiak P. Water column euxinia and wildfire evidence during deposition of the Upper Famennian Hangenberg event horizon from the Holy Cross Mountains (central Poland). Geol Magaz, 2007, 144: 569-595

174 Cao C, Love G D, Hays L E, et al. Biogeochemical evidence for euxinic oceans and ecological disturbance presaging the end-Permian mass extinction event. Earth Planet Sci Lett, 2009, 281: 188-201

175 van Bentum E C, Hetzel A, Brumsack H-J, et al. Reconstruction of water column anoxia in the equatorial Atlantic during the Cenomanian-Turonian oceanic anoxic event using biomarker and trace metal proxies. Palaeogeogr Palaeoclima Palaeoecol, 2009, 280: 489-498

176 Luo G, Kump L R, Wang Y, et al. Isotopic evidence for an anomalously low oceanic sulphate concentration following end-Permian mass extinction. Earth Planet Sci Lett, 2010, 300: 101-111

177 Schulz H N, Brinkhoff T, Ferdelman T G, et al. Dense populations of a giant sulfur bacterium in Namibian shelf sediments. Science, 1999, 284: 493-495

178 Kuypers M M M, Sliekers A O, Lavik G, et al. Anaerobic ammonium oxidation by anammox bacteria in the Black Sea. Nature, 2003, 422: $608-611$

179 Jenkyns H C, Matthews A, Tsikos H, et al. Nitrate reduction, sulfate reduction, and sedimentary iron isotope evolution during the Cenomanian-Turonian oceanic anoxic event. Paleoceanography, 2007, 22: 1-17

180 Kuypers M M M, Blokker P, Erbacher J, et al. Massive expansion of marine archaea during a Mid-Cretaceous oceanic anoxic event. Science, 2001, 293: 92-94

181 Okano K, Sawada K, Takashima R, et al. Further examples of archaeal-derived hydrocarbons in mid-Cretaceous Oceanic Anoxic Event (OAE) 1b sediments. Org Geochem, 2008, 39: 1088-1091 
182 Kah L C, Lyons T W, Frank T D. Low marine sulphate and protracted oxygenation of the Proterozoic biosphere. Nature, 2004, 431: $834-838$

183 Lowenstein T K, Hardie L A, Timofeeff M N, et al. Secular variation in seawater chemistry and the origin of calcium chloride basinal brines. Geology, 2003, 31: 857-860

184 Newton R J, Reeves E P, Kafousia N, et al. Low marine sulfate concentrations and the isolation of the European epicontinental sea during the Early Jurassic. Geology, 2011, 39: 7-10

185 Canfield D E, Farquhar J. Animal evolution, bioturbation, and the sulfate concentration of the oceans. Proc Natl Acad Sci USA, 2009, 106: $8123-8127$

186 Scholten J C M, Bodegom P M, Vogelaar J, et al. Effect of sulfate and nitrate on acetate conversion by anaerobic microorganisms in a freshwater sediment. FEMS Microbiol Ecol, 2002, 42: 375-385

187 Jørgensen B B. Mineralization of organic matter in the sea bed-the role of sulphate reduction. Nature, 1982, 296: 643-645

188 Valentine D L. Biogeochemistry and microbial ecology of methane oxidation in anoxic environments: A review. Anton Leeuw, 2002, 81: 271-282

189 Ventura G T, Kenig F, Reddy C M, et al. Molecular evidence of Late Archean archaea and the presence of a subsurface hydrothermal biosphere. Proc Natl Acad Sci USA, 2007, 104: 14260-14265

190 Li C, Love G D, Lyons T W, et al. A stratified redox model for the Ediacaran Ocean. Science, 2010, 328: 80-83

191 Poulton S W, Fralick P W, Canfield D E. Spatial variability in oceanic redox structure 1.8 billion years ago. Nat Geosci, 2010, 3: 486-490

192 Hurtgen M T, Pruss S B, Knoll A H. Evaluating the relationship between the carbon and sulfur cycles in the later Cambrian ocean: An example from the Port au Port Group, western Newfoundland, Canada. Earth Planet Sci Lett, 2009, 281: 288-297

193 Canfield D E, Glazer A N, Falkowski P G. The evolution and future of Earth nitrogen cycle. Science, 2010, 330: 192-196

194 Castro H, Ogram A, Reddy K R. Phylogenetic characterization of methanogenic assemblages in eutrophic and oligotrophic areas of the Florida everglades. Appl Environ Microbiol, 2004, 70: 6559-6568

195 Zehr J P, Kudela R M. Nitrogen cycle of the open ocean: From genes to ecosystems. Annu Rev Mar Sci, 2011, 3: 197-225

196 Mahaffey C, Michaels A F, Capone D G. The conundrum of marine $\mathrm{N}_{2}$ fixation. Am J Sci, 2005, 305: 546-595

197 Moore M C, Mills M M, Achterberg E P, et al. Large-scale distribution of Atlantic nitrogen fixation controlled by iron availability. Nat Geosci, 2009, 2: 867-871

198 Saito M A, Bertrand E M, Dutkiewicz S, et al. Iron conservation by reduction of metalloenzyme inventories in the marine diazotroph Crocosphaera watsonii. Proc Natl Acad Sci USA, 2011, 108: 2184-2189

199 Deutsch C, Sarmiento J L, Sigman D M, et al. Spatial coupling of nitrogen inputs and losses in the ocean. Nature, 2007, 445: 163-167

200 Levitan O, Rosenberg G, Setlik I, et al. Elevated $\mathrm{CO}_{2}$ enhances nitrogen fixation and growth in the marine cyanobacterium Trichodesmium. Glob Change Biol, 2007, 13: 531-538

201 Xie S, Pancost R D, Wang Y, et al. Cyanobacterial blooms tied to volcanism during the 5 m.y. Permo-Triassic biotic crisis. Geology, 2010, 38: $447-450$

202 Shi D, Xu Y, Hopkinson B M, et al. Effect of ocean acidification on iron availability to marine phytoplankton. Science, 2010, 327: 676-679

203 Mort H P, Adatte T, Follmi K B, et al. Phosphorus and the roles of productivity and nutrient recycling during oceanic anoxic event 2. Geology, 2007, 35: 483-486

204 Lehmann B, Nagler T F, Holland H D, et al. Highly metalliferous carbonaceous shale and Early Cambrian seawater. Geology, 2007, 35: 403-406

205 Klein C. Some Precambrian banded iron-formations (BIFs) from around the world: Their age, geological setting, mineralogy, metamorphism, geochemistry, and origin. Am Mineral, 2005, 90: 1473-1499

206 Canfield D E, Habicht K S, Thamdrup B. The Archean sulfur cycle and the early history of atmospheric oxygen. Nature, 2000, 288: 658-661

207 Holland H. The oxygenation of the atmosphere and oceans. Philos Trans R Soc Lond B, 2006, 361: 903-915

208 Posth N R, Hegler F, Konhauser K O, et al. Alternating Si and Fe deposition caused by temperature fluctuations in Precambrian oceans. Nat Geosci, 2008, 1: 703-708

209 Konhauser K O, Amskold L, Lalonde S V, et al. Decoupling photochemical Fe(II) oxidation from shallow-water BIF deposition. Earth Planet Sci Lett, 2007, 258: 87-100

210 Planavsky N, Rouxel O, Bekker A, et al. Iron-oxidizing microbial ecosystems thrived in late Paleoproterozoic redox-stratified oceans. Earth Planet Sci Lett, 2009, 286: 230-242

211 Li Y, Konhauser K O, Cole D R, et al. Mineral ecophysiological data provide growing evidence for microbial activity in banded-iron formations. Geology, 2011, 29: 707-710 